\title{
Seasonal transformation and spatial variability of water masses within MacKenzie polynya, Prydz Bay
}

\author{
Esther Portela ${ }^{1,2}$, Stephen R. Rintoul ${ }^{3,4,5}$, Sophie Bestley ${ }^{1,4}$,Laura \\ Herraiz-Borreguero ${ }^{3,5}$, Esmee van Wijk ${ }^{3,4}$, Clive R. McMahon ${ }^{1,6}$, Fabien \\ Roquet $^{7}$ and Mark Hindell ${ }^{1}$ \\ ${ }^{1}$ Institute for Marine and Antarctic Studies, University of Tasmania, Hobart 7001, Australia \\ ${ }^{2}$ Univ. Brest, Laboratoire d'Océanographie Physique et Spatiale, CNRS, IRD, Ifremer, Plouzané, France \\ ${ }^{3}$ CSIRO Oceans and Atmosphere, Hobart 7001, Australia \\ ${ }^{4}$ Australian Antarctic Program Partnership, Institute for Marine and Antarctic Studies, University of \\ Tasmania, Hobart 7001, Australia \\ 5 Centre for Southern Hemisphere research (CSHOR), Australia \\ ${ }^{6}$ Integrated Marine Observing System Animal Tagging sub-Facility, Sydney Institute of Marine Science, \\ Mosman 2088, Australia \\ ${ }^{7}$ Department of Marine Sciences, University of Gothenburg, Gothenburg 40530, Sweden
}

\section{Key Points:}

- High resolution sampling of seasonal water-mass evolution in MacKenzie Polynya reveals processes regulating dense shelf water production

- Dense water formation is concentrated in the relatively shallow western polynya where topography blocks inflow of fresh Ice Shelf Water

- The interplay between sea ice formation, meltwater input and topography regulates the amount of Dense Shelf Water formed in coastal polynyas 


\begin{abstract}
We provide a detailed description of the spatial distribution, seasonality and transformation of the main water masses within MacKenzie Polynya (MP) in Prydz Bay, East Antarctica, using data from instrumented southern elephant seals. Dense Shelf Water (DSW) formation in MP shows large spatial variability that is related to the (i) local bathymetry, (ii) water column preconditioning from the presence/absence of different water masses, and (iii) proximity to the Amery Ice Shelf meltwater outflow. MP exhibits sustained sea ice production and brine rejection (thus, salinity increase) from April to October. However, new DSW is only formed from June onward, when the mixed layer deepens and convection is strong enough to break the stratification set by Antarctic Surface Water above and Ice Shelf Water below. We found no evidence of DSW export from MP to Darnley polynya, as previously suggested. Rather, our observations suggest some DSW formed in Darnley Polynya may drain towards the western Prydz Bay. Then, DSW is exported offshore from Prydz Bay through the Prydz Channel. The interplay between sea ice formation, meltwater input, and sea floor topography is likely to explain why some coastal polynyas form more DSW than others, as well as the temporal variability in DSW formation within a particular polynya.
\end{abstract}

\title{
Plain Language Summary
}

Coastal polynyas are regions of open water surrounded by sea ice. They form when strong winds from the Antarctic continent push newly-formed sea ice away from the coast, as rapidly as it forms. Polynyas are therefore important sea ice factories. When sea ice forms, salt is released into the water below, increasing its salinity and density. The densest water in the World Ocean can be traced back to a few coastal polynyas along the Antarctic continent. This dense water formed in polynyas supplies the deep limb of a network of ocean currents that influences climate on global scales. Despite their importance, coastal polynyas remain poorly understood as they are difficult to reach and observe. Using data collected by instrumented elephant seals, we investigated seasonal changes in the MacKenzie Polynya in Prydz Bay, East Antarctica. Our study shows that dense water production is regulated by a complex interplay between three factors: strength of sea ice formation, the input of meltwater from ice shelves, and steering of the flow by sea floor topography. These new observations collected by seals contribute to a better understanding of dense water formation and the vulnerability of the global overturning circulation to future change.

\section{Introduction}

Coastal polynyas are regions of open water or low ice concentration where the ocean is directly exposed to the cold atmosphere. Persistent wind-driven sea ice export and heat loss in coastal polynyas results in continuous sea ice formation and brine rejection in winter. The cooling and salinification of the waters within polynyas during sea ice formation drive strong buoyancy loss and the formation of Dense Shelf Water (DSW), which is the precursor to Antarctic Bottom Water (AABW). AABW, the densest water mass in the ocean, is formed around Antarctica and transports cold, saline water to lower latitudes, ventilating the ocean abyss (Orsi et al., 2002; Foster \& Carmack, 1976). Understanding the dynamics of coastal polynyas is critical to quantifying the sensitivity of AABW to changes in forcing and the future behavior of the deep overturning circulation. East Antarctic coastal polynyas also regulate the transport of ocean heat to the floating ice shelves fringing the Antarctic continent (Silvano et al., 2016). Export of DSW requires a compensating inflow of water from the open ocean (Morrison et al., 2020), which might increase heat supply to the continental shelf. On the other hand, strong air-sea heat loss in polynyas can remove heat from the ocean before it reaches the ice shelves. Previous studies have investigated seasonal and regional differences in the distribution of water masses in Antarctic polynyas from observations (Narayanan et al., 2019; Amblas \& Dowdeswell, 2018). However, given the 
limited number of observations at these high latitudes, the influence of polynyas on AABW formation remains poorly understood.

Prydz Bay is a deep embayment along the East Antarctic coast (Figure 1). It is downstream from the Lambert Glacier - Amery Ice Shelf drainage system, which drains $\approx 16 \%$ of the East Antarctic Ice Sheet (Fricker et al., 2000). On the eastern side of the bay, the seafloor shoals to depths of $200 \mathrm{~m}$ at the Four Ladies Bank (FLB in Figure 1) (O'Brien et al., 2004). On the western side of Prydz Bay, the Amery Depression is linked to the shelf break by the Prydz Channel, which is around $100 \mathrm{~km}$ wide, and its depth ranges from 700 $\mathrm{m}$ at its inshore end to $\approx 500 \mathrm{~m}$ at the shelf break.

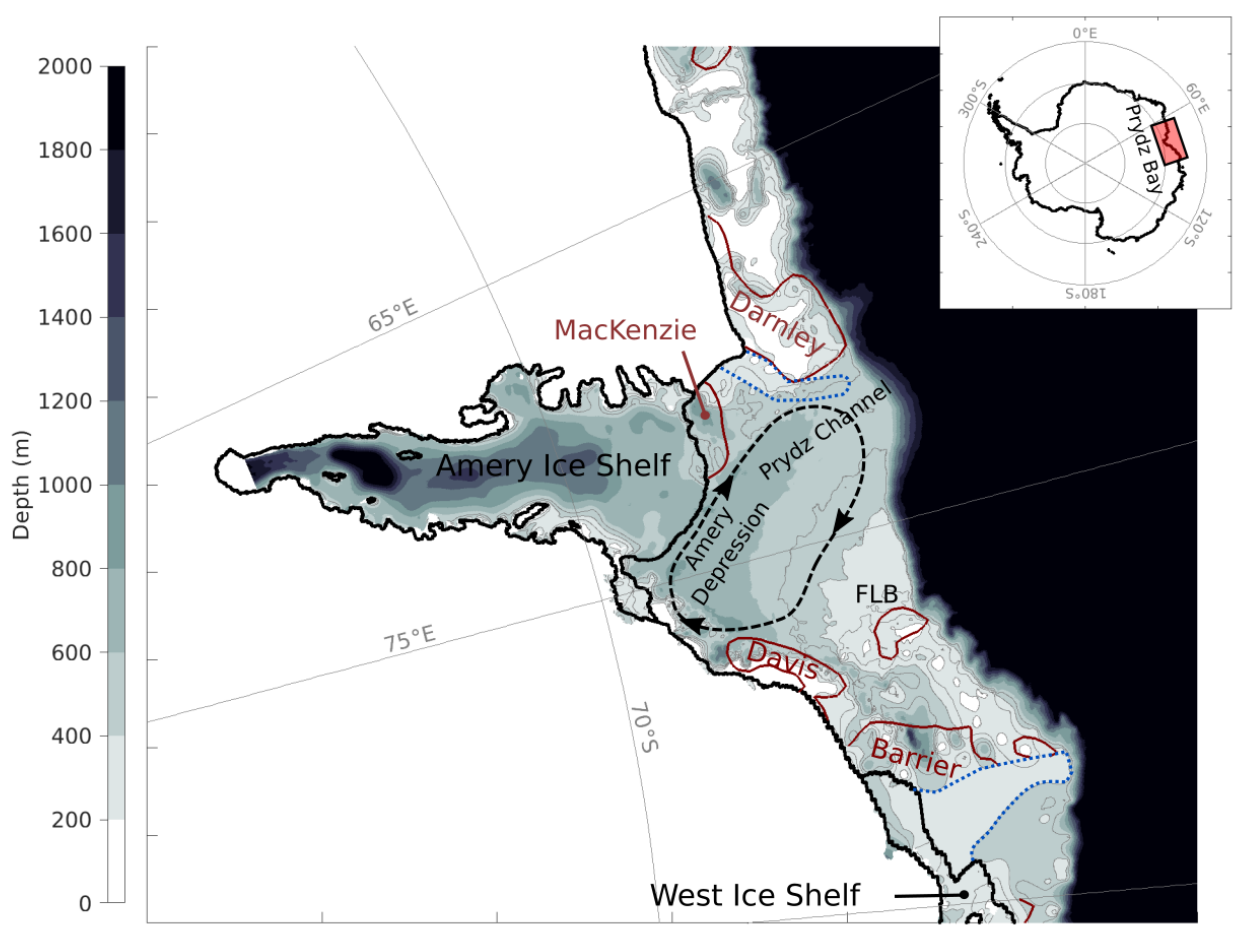

Figure 1. The Prydz Bay region and its main features. The four polynyas in and around the bay are delimited with brown contours, and they are from east to west: Barrier, Davis, MacKenzie and Darnley. The cyclonic gyre, centered on the Amery Depression and Prydz Channel, is shown with a dashed black line. The blue dotted contours define the approximate mean position of the most important fast ice structures within Prydz Bay as shown by satellite imaging (https://worldview.earthdata.nasa.gov/).

The ocean circulation in Prydz Bay consists of a large cyclonic gyre, centered in the Amery Depression (Nunes Vaz \& Lennon, 1996; Smith et al., 1984). The gyre is associated with a relatively narrow coastal current that brings modified Circumpolar Deep Water (mCDW) from the eastern flank of the bay to the eastern Amery Ice Shelf calving front. The flow strengthens along the western side of Prydz Bay, with speeds exceeding $1 \mathrm{~m} \mathrm{~s}^{-1}$ (Nunes Vaz \& Lennon, 1996) and continues westward after leaving the bay. Around April, at the beginning of the austral winter, $\mathrm{mCDW}$ enters the Amery ice shelf cavity, causing basal melt of up to $2 \mathrm{~m} \mathrm{yr}^{-1}$ as computed from observations during 2001 (Herraiz-Borreguero et al., 2015). Baroclinic eddies, which are formed during winter deep convection (down to 1100 $\mathrm{m}$ ), also drive inflow of DSW formed in Mackenzie polynya (MP) into the ice shelf cavity (Herraiz-Borreguero et al., 2016). DSW is observed in front of the ice shelf calving front in 
the summer months, beneath the summer mixed layer and the Ice Shelf Water (ISW) plume (when present). Due to the pressure dependence of the seawater freezing point, this DSW is warmer than the local in situ freezing point at depth and is therefore able to melt the basal surface of the ice shelf. (Herraiz-Borreguero et al., 2016; Silvano et al., 2016).

The presence of three polynyas within Prydz Bay (Barrier, Davis and MacKenzie from east to west), suggests this region may be important for sea ice and DSW formation in East Antarctica. Moreover, Cape Darnley polynya, located due west of Prydz Bay, is one of the most active regional polynyas in terms of sea ice production (Tamura et al., 2008, 2016) and DSW formation (Ohshima et al., 2013; Aoki, Yamazaki, et al., 2020). Cape Darnley receives the westward coastal current after it leaves Prydz Bay (Nunes Vaz \& Lennon, 1996) with an associated water-mass exchange between them. Previous studies have described the watermass distribution and the role that ISW and mCDW play in controlling the formation rates and thermohaline properties of DSW within Prydz Bay (Herraiz-Borreguero et al., 2015, 2016; Guo et al., 2019; Williams et al., 2016; A. P. S. Wong et al., 1998; W. Liu et al., 2018; Sabu et al., 2021). However, little attention has been paid to the water-mass distribution, properties and transformation within a particular polynya in relation to its bathymetry and hydrographic characteristics.

MP, the polynya best sampled by instrumented southern elephant seals (Mirounga leonina) within Prydz Bay (Williams et al., 2016), occurs on the western flank of the Amery calving front between April and October. It is responsible for an average cumulative annual sea ice production of $68.2 \mathrm{~km}^{3}$ (over an average area of $3.9 \times 10^{3} \mathrm{~km}^{2}$ ) (Tamura et al., 2008), which makes it one of the ten highest ice-production polynyas in the Southern Ocean (Tamura et al., 2016; Nakata et al., 2021). Our study builds on previous studies of the role of polynyas in DSW formation within and around Prydz Bay (Williams et al., 2016; Herraiz-Borreguero et al., 2016; Ohshima et al., 2013) and in particular within MP (Xu et al., 2017). Here, we are interested in the seasonal transformation of the water masses within the MP. We document in detail the spatial variability of water-mass properties and highlight the influence of bathymetry on the water-mass distribution and DSW formation in MP. The main pathways of DSW export from Prydz Bay are also discussed.

The unprecedented detail provided by seal-observed oceanographic data (McMahon et al., 2021) in MP provides new insights into the governing processes in a coastal polynya that is influenced by both strong sea ice formation and high input of glacial meltwater. The MP may illustrate how other coastal polynyas will respond to the future increase of fresh meltwater input in response to a changing climate. Our study therefore has implications for the design of sampling programs investigating water mass transformation and its sensitivity to change. The knowledge of physiographic features that favor (or inhibit) DSW formation can be used to target key regions and optimize sampling efforts, including the use of novel autonomous devices (Gwyther et al., 2020; Aoki, Ono, et al., 2020).

This paper is organized as follows: in section 2, we introduce and describe the main water masses in Prydz Bay. Section 3 describes the data used, the methods of polynya identification and the computation of sea ice production (SIP). In section 4, we present the main results, including the seasonal transformation of water-masses, their distribution, and their spatial variability with a special focus on DSW formation and export pathways within MP. Finally, in section 5, we provide an overview of our results, and we discuss our main findings and how they compare with previous studies.

\section{Water masses in Prydz Bay}

Three water masses have been reported to be important within Prydz Bay: mCDW, DSW, and ISW (Smith et al., 1984; Orsi \& Wiederwohl, 2009; Whitworth et al., 1998). The Antarctic Surface water (AASW), also described in this region (Whitworth et al., 1998; A. P. S. Wong et al., 1998; Orsi \& Wiederwohl, 2009) has received less attention in the 
literature but, since it is ubiquitous in summer and still present in early winter, we found it to be important for seasonal water-mass transformation.

CDW is the warmest subsurface water mass offshore from the Antarctic continental shelf. When CDW intrudes onto the continental shelf, it undergoes strong mixing with the winter water above and across the Antarctic slope front (Whitworth et al., 1998; Orsi \& Wiederwohl, 2009). The resulting water mass found on the shelf in some areas is much fresher and colder than its offshore source, and it is named modified (m)CDW (Foster \& Carmack, 1976). Typically, mCDW is defined by a neutral density between 28.0 and 28.27 $\mathrm{kg} \mathrm{m}^{-3}$ and $\theta$ more than $0.1^{\circ} \mathrm{C}$ above the surface freezing point (Table 1 ).

AASW is a water mass of variable thickness that sits above the permanent pycnocline. Because of its location at the air-sea-ice interface, AASW is the most variable in properties of all Antarctic water masses. It undergoes strong seasonal transformation due to air-sea fluxes, so AASW temperature and salinity experience large fluctuations: AASW salinity ranges from less than 33 to about 34.5, and its temperature ranges from the surface freezing point to more than $-1^{\circ} \mathrm{C}$. Winter buoyancy loss progressively transforms the warm and fresh AASW into a colder and saltier, hence denser, water mass that has been defined by some authors as Winter Water (Whitworth et al., 1998; A. P. S. Wong et al., 1998). However, for simplicity, in this study, we will not differentiate between the Winter Water (remnant of previous winter) and the warmer and fresher Summer Surface Water (A. P. S. Wong et al., 1998), and we will refer to both types as AASW (as in Sabu et al. (2021)). In coastal polynyas with sufficient sea ice formation, the resulting winter convection and mixed layer deepening mixes the AASW with the underlying water masses to eventually form DSW (Baines et al., 1998).

DSW, formed in coastal polynyas, is the densest water mass on the Antarctic continental shelf (Rintoul, 1998; Gordon \& Tchernia, 1972; Herraiz-Borreguero et al., 2016) and is defined over a narrow T-S range (Table 1). DSW forms when winter cooling and salinification during sea ice formation drives strong convection over the water column. With sufficient negative buoyancy and an export pathway across the shelf break, DSW mixes down the continental slope with ambient water masses to produce AABW (Ohshima et al., 2013). Modified Shelf Water $(\mathrm{mSW})$ is defined as water denser than $\gamma=28.27 \mathrm{~kg} \mathrm{~m}^{-3}$, warmer than DSW and whose temperature falls below $-1.7^{\circ} \mathrm{C}$ (Orsi \& Wiederwohl, 2009; Foster \& Carmack, 1976). mSW can be found (i) on the continental slope, formed when the overflowing DSW meets the ambient slope water (mainly $\mathrm{mCDW}$ ) or (ii) on the shelf from mixing between the ambient DSW and inflowing mCDW. In both cases, $\mathrm{mSW}$ is the result of mixing between $\mathrm{mCDW}$ and DSW and shows T-S characteristics intermediate between these water masses. The mSW found on the slope is considered to be the precursor of AABW (Orsi \& Wiederwohl, 2009; Foster \& Carmack, 1976; Ohshima et al., 2013; Williams et al., 2008).

ISW, defined by a potential temperature below the surface freezing point (Table 1), is the coldest water mass in Prydz Bay. To avoid confusion between ISW and super-cooled water near the sea surface (Haumann et al., 2020), we define ISW to be water cooler than the surface freezing point and deeper than $100 \mathrm{~m}$ depth. After visually exploring the available data, the threshold of $100 \mathrm{~m}$ depth was made because no ISW was ever found in the upper $100 \mathrm{~m}$ of the water column, and conversely super-cooled surface waters were not found deeper than this depth. ISW forms when the deepest water mass on the shelf (DSW or $\mathrm{mCDW}$ ) accesses the ice-shelf cavity and produces glacial meltwater through basal ice shelf melt. We refer to ISW as the mixture of glacial meltwater and ambient seawater with temperature below the surface freezing point. This meltwater is positively buoyant due to its low salinity, so it ascends and mixes until it reaches a level of neutral buoyancy, above or within the layer of its source water mass. The resulting mixture is defined as ISW if its temperature is colder than the surface freezing point (Herraiz-Borreguero et al., 2016; C. Liu et al., 2018; Bindoff et al., 2001). 
Table 1. Water-mass classification based on Herraiz-Borreguero et al. (2016, 2015); Williams et al. (2016) and Orsi and Wiederwohl (2009).

\begin{tabular}{cccc}
\hline Water mass & Salinity & Potential temperature & Neutral density \\
\hline AASW & $S<34.4$ & $\theta>T_{f}$ & $\gamma<28$ \\
mCDW & - & $\theta>T_{f}+0.1$ & $28<\gamma<28.27$ \\
ISW & - & $\theta<T_{f}-0.05$ & - \\
DSW & $S>34.5$ & $T_{f}-0.05<\theta<T_{f}+0.1$ & $\gamma>28.27$ \\
mSW & - & $T_{f}+0.1<\theta<-1.7$ & $\gamma>28.27$ \\
\hline
\end{tabular}

$* T_{f}$ : surface freezing point.

\section{Methods}

\subsection{Data}

In this study, we have used vertical temperature-salinity profiles collected by southern elephant seals instrumented with Conductivity-Temperature-Depth Satellite-Relay Data Loggers (CTD-SRDLs) during their annual post-moult foraging trips. Elephant seals have been very effective Southern Ocean samplers (Roquet et al., 2014), particularly in providing almost all the available data within polynyas during winter (Labrousse et al., 2018; Malpress et al., 2017). The profile data were retrieved from the Marine Mammals Exploring the Oceans Pole to Pole (MEOP) database (http://www.meop.net/), which is a comprehensive quality-controlled database (Roquet et al., 2014).

Multiple seals sampled Prydz Bay between 2009 and 2017 but, within the MP, there are no data before 2011, and most of the sampling was carried out between 2011 and 2013. The time series of data collected by each seal within the MP over the whole period is shown in Figure 2. The longest periods are observed in 2012 and 2013, the latter sampling being carried out by one individual seal between March and October. However, in 2011 we have the benefit of different seals sampling simultaneously within the MP between April and June. This simultaneous sampling in 2011 allows the spatial variability inside the polynya to be described, while the sampling in 2013 by a single seal in a very restricted location allowed for a detailed look at the seasonal evolution of DSW.

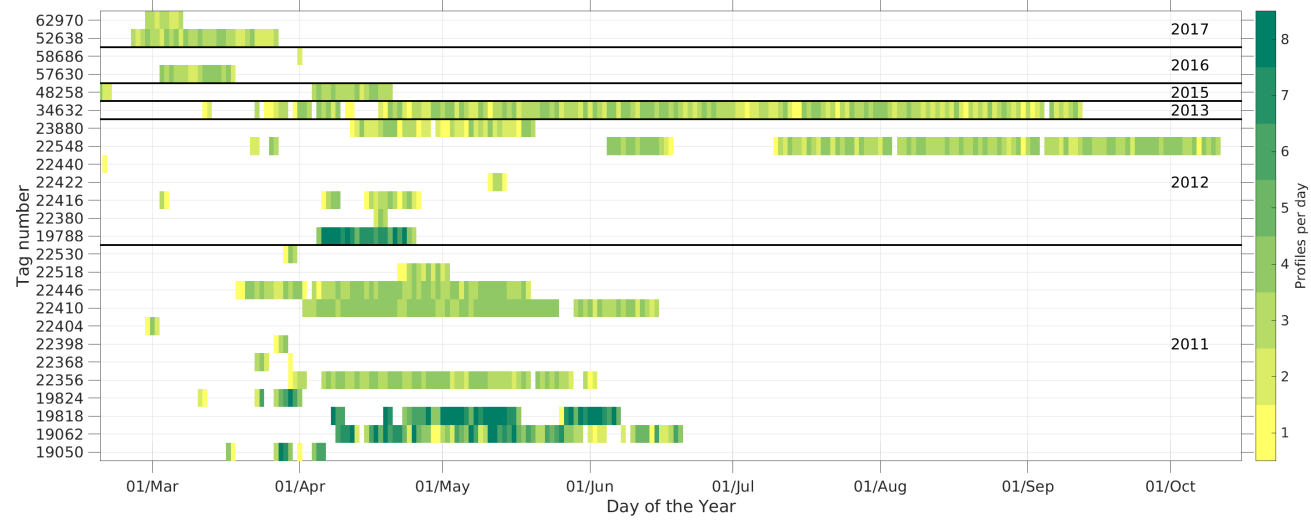

Figure 2. Number of seal profiles per day in MP between 2011 and 2017. 
The bathymetry of Prydz Bay was obtained from Schaffer et al. (2019), (https://doi.org/ 10.1594/PANGAEA.905295). The monthly sea-ice concentration dataset estimated from $\mathrm{SSM} / \mathrm{I}$ was used to identify the polynya boundaries at a resolution of $12.5 \mathrm{~km}$. It was obtained from ftp://ftp.ifremer.fr/ifremer/cersat/products/gridded/psi-concentration/data/.

\subsection{Polynya identification}

We identified polynyas using a combination of dynamic sea-ice concentration and static bathymetric data. First, Prydz Bay was divided into coarse-scale polygons, each one containing one polynya as based on previous descriptions in the literature (Arrigo \& van Dijken, 2003; Labrousse et al., 2018; Tamura et al., 2016; Amblas \& Dowdeswell, 2018). After this first identification, two criteria were used to define the area of each polynya and to assign seal CTD profiles to them. In winter (from April to October), monthly sea-ice concentration contours of $75 \%$ within each polygon were selected, and all data inside those contours were assigned to belong to the given polynya. The criterion of $75 \%$ was visually examined and compared with lower values of sea ice concentration (at $5 \%$ intervals from $60 \%$ to $75 \%$ ), but the shape and extent of the polynya showed little variation. In order to include more data in our analyses and following Massom et al. (1998) and Xu et al. (2017), the 75\% threshold was used. With this method, polynya surface area changes monthly. In summer (from November to March), when most of the region is indeed ice-free, we assigned CTD profiles that were located within the $75 \%$ contours of mean sea-ice concentration between April and October of the preceding winter. To avoid including data off the continental shelf, the contours are further constrained by the continental slope (defined by depths $>1500 \mathrm{~m}$ ).

\subsection{Sea Ice Production (SIP)}

In coastal polynyas, SIP is directly related to the formation and evolution of DSW. The surface layer salinifies quickly due to ocean heat loss and subsequent brine rejection during the sea ice formation season. The increase in salinity, and so density, drives convection and mixing with the underlying water masses, ultimately forming DSW. Therefore, the computation of the SIP provides insight on a key mechanism for the seasonal water mass transformation inside polynyas. In this study, the sea ice formation rate $\left(V_{i}\right)$ has been computed based on the method of Charrassin et al. (2008). To minimise aliasing of spatial variability, we used data from an individual seal that sampled in a restricted location during 2013 between times t 1 and $t 2$ during the ice formation season. This method estimates SIP from the increase in salinity between $\mathrm{t} 1$ and $\mathrm{t} 2$.

$$
V_{i}=\frac{\rho_{0}\left(V_{t_{1}} S_{t_{1}}-V_{t_{2}} S_{t_{2}}\right)}{\rho_{i} S_{i}}
$$

where $\rho_{0}=1027 \mathrm{~kg} \mathrm{~m}^{-3}$ is a reference density of seawater, $\rho_{i}=920 \mathrm{~kg} \mathrm{~m}^{-3}$ is the sea ice density, $S_{i}=10$ is the salinity of the sea ice formed, $V_{t_{1}}$ is the initial volume of water at time $t_{1}$, with salinity $S_{t_{1}}$; and $V_{t_{2}}=V_{t_{1}}-V_{i}$ is the volume of seawater at time $t_{2}$, with salinity $S_{t_{2}}$.

Here we calculate the mean salinity over the first $300 \mathrm{~m}$ of the water column. This depth was chosen as an 'ad hoc' criterion for the particular small region in the western MP sampled by the single seal in 2013. This choice represents a compromise between having a sufficient number of CTD profiles reaching this depth $(300 \mathrm{~m})$ and considering a thick enough layer to have a representative quantity. Moreover, in 2013, the bottom of the dive also reached $\approx 300 \mathrm{~m}$ on average, and from June, full convection to this depth is achieved.

This method has been used in a number of studies (Labrousse et al., 2018; Williams et al., 2011) but it has three main shortcomings: (i) it neglects the contribution of lateral advection and precipitation to the salinity change, (ii) the fixed depth over which the mean salinity increase is computed can result in underestimation of SIP when convection exceeds 
$300 \mathrm{~m}$ depth, and (iii) it does not account for the spatio-temporal variability of the salinity sampling by the seals. To minimize the effect of these limitations, we restrict the computation of SIP to profiles collected by a single seal in the western part of the MacKenzie Polynya during 2013. Here, little mCDW or ISW reaches the shallower bathymetry (see below), reducing the impact of lateral advection, and the small region sampled by this seal reduces the impact of variable spatial sampling on the salinity budget and SIP computation. Comparison between seal-derived and satellite-derived SIP have been previously performed by Tamura et al. (2016) during 2013. These authors found good agreement between these two datasets both in total magnitude (difference within $20 \%$ ) and monthly variability.

In MP, the inflow of mCDW is limited (Herraiz-Borreguero et al., 2015; Williams et al., 2016; Xu et al., 2017; C. Liu et al., 2018), and therefore its contribution to changes in the salinity budget is likely to be small. In contrast, the inflow of ISW might be significant (Herraiz-Borreguero et al., 2015; Williams et al., 2016; Xu et al., 2017) which might result in a non-negligible contribution of advection to the SIP. To provide further insight on the uncertainties associated with the choices made in the SIP computations, Figure S1 (supplementary information) shows the SIP computed over the first $100 \mathrm{~m}$ of the water column and without the influence of ISW. Despite the role of advection, which we cannot quantify, when the seals sample in a single location (analogous to a mooring), we assume that the main contribution to the salinity changes is the seasonal evolution of the water masses, mainly driven by SIP. In this study, over the sampling period, convection episodically reached the seafloor when it was deeper than $300 \mathrm{~m}$, so the SIP rate could be underestimated.

\section{Results}

\subsection{Seasonal water-mass variability}

Here we describe the seasonality of the main water masses within Prydz Bay from three perspectives. First, we provide an overview of the horizontal distribution of the water masses across the whole of Prydz Bay, providing regional context for the MP. Second, we focus on the MP and describe the seasonality of (i) its T-S features and (ii) the vertical distribution of the main water masses. Due to sampling limitations, interannual variability is not specifically addressed in this study, although some qualitative comparisons can be made between 2011 and 2013, the three years with the longest time series. In this section we use a different color palette to represent each water mass. This allows us to illustrate their spatial and temporal distribution as well as the seasonal evolution of the salinity of each water mass.

\subsubsection{Horizontal distribution}

The horizontal distribution of the four main water masses in Prydz Bay between March and October is shown in Figure 3. The periods were grouped in order to have a representative amount of data in each plot over months with similar characteristics. Only the maximum salinity per profile for each water mass is shown in Figure 3.

mCDW (Figure 3a-e) extends over most of Prydz Bay in late summer (March). The exceptions are the MacKenzie and Barrier polynyas, where its presence is limited over this period and negligible the rest of the year (the area sampled also decreases during the year, as the ice cover increases and the seals retreat from the ice-covered regions). In May, mCDW is no longer observed within Cape Darnley, and in winter (June-July), only a few profiles with relatively cold mCDW (not shown) are found near the edge of the Cape Darnley polynya. In contrast, mCDW is always present offshore and shows little apparent seasonal variability. The sporadic presence of $\mathrm{mCDW}$ on the shelf may reflect: (i) seasonal variability in the mCDW inflow, (ii) the lack of observations in the ice-covered region and, (iii) winter transformation of mCDW as it crosses the shelf and in polynyas. The overflow of DSW down the continental slope in winter may be compensated by inflow of mCDW onto the 

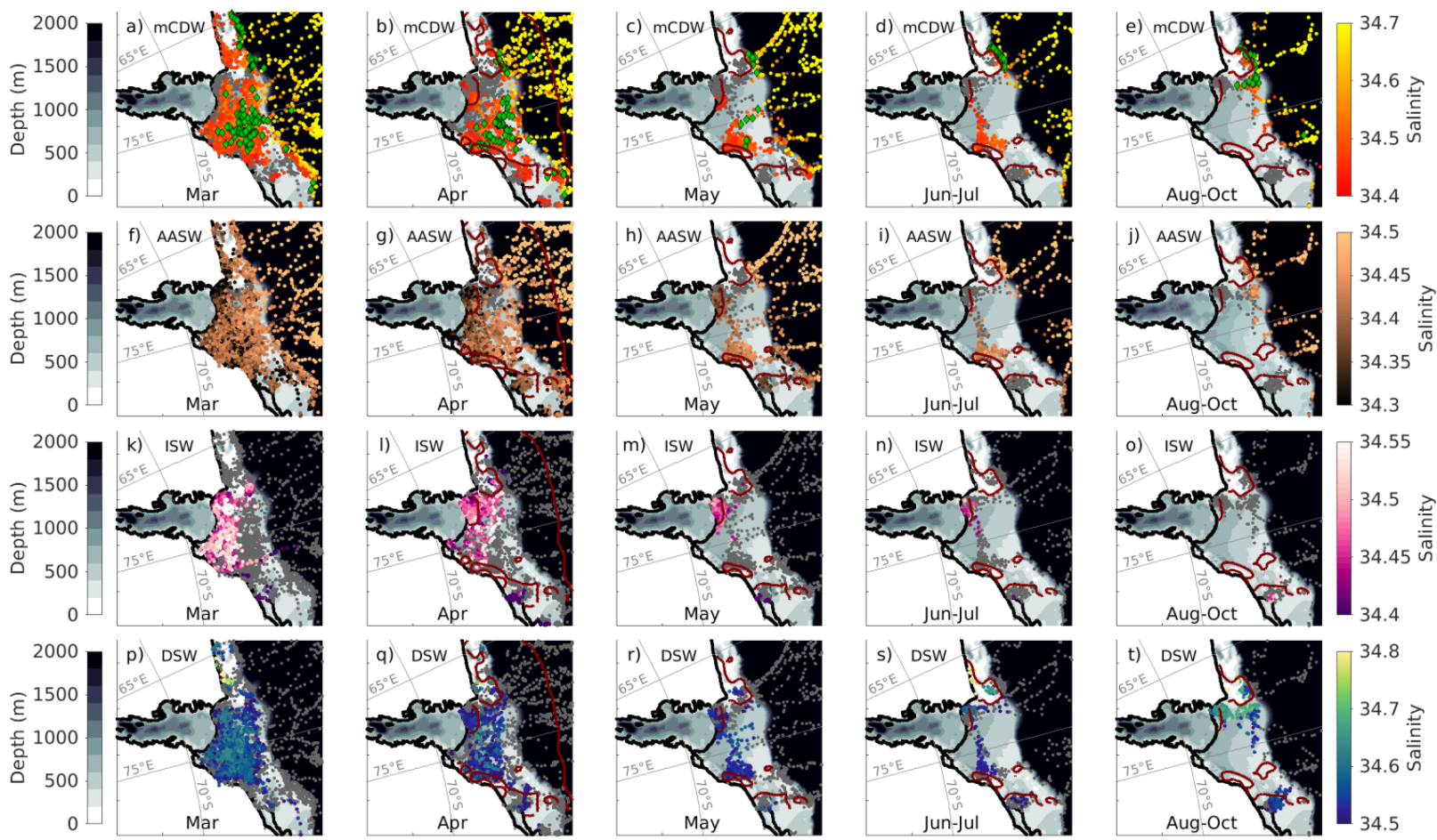

Figure 3. Seasonal distribution of the main water masses in the Prydz Bay region. (a-e) mCDW, with green diamonds highlighting mSW, (f-j) AASW, (k-o) ISW, and (p-t) DSW. The temporal evolution is March (first column), April (second column), May (third column), June-July (fourth column) and August-October (last column). The plots comprise years from 2009 to 2017 and, in order to minimise overplotting, only the maximum salinity per profile for each water mass is plotted. The water mass definition used here follows Table 1 . The brown contours show the polynya area as the 2009-2017 climatological mean for each month.

shelf (Morrison et al., 2020) that does not appear in the seal observations because the seal avoid regions with heavy ice cover. This could explain the occasional occurrence of mCDW observed on the continental shelf in June-October.The salinity of mCDW is maximum at the slope and in the open ocean, and it decreases strongly over the shelf, consistent with observations from Williams et al. (2016).

$\mathrm{mSW}$, a water mass warmer than DSW but denser (therefore saltier) than mCDW, is highlighted by green diamonds in Figure 3 (a-e). This water mass represents the mixing between the salty DSW and the warm mCDW (Orsi \& Wiederwohl, 2009) and is a precursor for AABW when found on the continental slope (Mizuta et al., 2021; Ohshima et al., 2013). AABW only exists in the open ocean, where it is too deep to be sampled by the seals, but the presence of $\mathrm{mSW}$ on the slope highlights the pathways of DSW exported from the Prydz Bay and Cape Darnley polynyas. mSW is also observed in eastern Prydz Bay in late summer (Figure 3a) and between Darnley and Mackenzie polynyas in August-October (Figure 3e). In those cases, the presence of mSW indicates locations where DSW encounters inflowing mCDW on the shelf and therefore also provides information about the export pathway of DSW formed in the Prydz Bay polynyas. 
AASW (Figure $3 \mathrm{f}-\mathrm{j}$ ) has a similar distribution to that of $\mathrm{mCDW}$, with the key difference that it is also present in Mackenzie and Barrier polynyas between March and May. The relatively warm and fresh properties of AASW are reduced over time due to atmospheric cooling, brine rejection, and convective winter mixing. In contrast to mCDW, AASW salinity does not show a clear cross-shelf gradient, but it tends to be fresher in the MP region.

ISW (Figure $3 \mathrm{k}-\mathrm{o}$ ) is widespread along the ice shelf calving front in late summer (March-April) (Figure $3 \mathrm{k}-\mathrm{l}$ ). Its salinity ranges from 34.4 to 34.55 , and the freshest type of ISW is found within the Barrier Polynya. The spatial extent of ISW is largest in April (Figure 31) when it extends north to the eastern flank of the Darnley polynya. During winter, ISW is only found near the western side of the Amery ice shelf, mainly within the MP. This is related to the location of the main meltwater outflow (Herraiz-Borreguero et al., 2016, 2015; Williams et al., 2016). While seals did not sample along the eastern edge of the calving front in winter, previous studies with moorings in this region have shown that ISW is absent between April and August but sporadically observed from August to December (Herraiz-Borreguero et al., 2016). By August-October, ISW is absent from inshore regions, except for a small remnant in Barrier Polynya (Figure 3o).

DSW (Figure 3p-t) extends over the whole Prydz Bay-Cape Darnley shelf region in March. The salinity of DSW declines in April and reaches a minimum in May, when only the freshest type of DSW (salinity $\approx 34.5-34.65$ ) is observed. In June and July, DSW is also ubiquitous inside polynyas, with the maximum salinity $(\approx 34.8)$ found in Cape Darnley. By late winter (August - October) DSW is the dominant water mass on the shelf, with a salinity $>34.7$ over the sampled region that includes Barrier Polynya and western Prydz Bay.

The largest seasonal variations in DSW salinity are observed within the MP: the freshest DSW is observed between April and May, followed by a salinity increase from June to October. The seasonality of DSW in Cape Darnley is difficult to assess with the current data set, as different areas are not sampled in the same seasons. The western edge of the Cape Darnley polynya, near the coast, shows very saline DSW whenever it is sampled (in March and in June-July) relative to the rest of the Cape Darnley polynya. This may reflect the fact that polynyas near the coast experience the strongest katabatic wind forcing, and open water persists for a longer period. During the rest of the year, this region is not sampled by the seals, and DSW salinity in the remainder of the Cape Darnley polynya is similar to that observed in MP.

\subsubsection{Seasonal T-S features within Mackenzie Polynya}

The T-S water properties in Figure 4 highlight the seasonal evolution of the water masses within the MP. The first feature that stands out is the strong water-mass transformation that takes place in the MP from March to October. MP is particularly well sampled during this period, so the data spread in T-S space mostly reflects the water-mass variability and the spatial variability inside the polynya, rather than data availability.

In March (Figure 4 left column (a,f,k,p)), the waters found in the MP range between -2.1 ${ }^{\circ} \mathrm{C}$ and $0.5{ }^{\circ} \mathrm{C}$ in temperature and between 33.5 and 34.6 in salinity. From April onward, the upper water masses (notably AASW) undergo progressive salinification and cooling, with the temperature approaching the surface freezing point (horizontal black line in Figure 4). Both AASW and mCDW are completely transformed, or no longer observed, by June.

The T-S features of the ISW are quite stable. This suggests that this water mass does not experience substantial mixing until August, when deep convection reaches deep enough to erode the ISW signal (Herraiz-Borreguero et al., 2016). The final product of this seasonal evolution (cooling and brine rejection) and intense winter mixing in MP is DSW formation and its progressive densification. However, DSW is present at depth in MP throughout the 

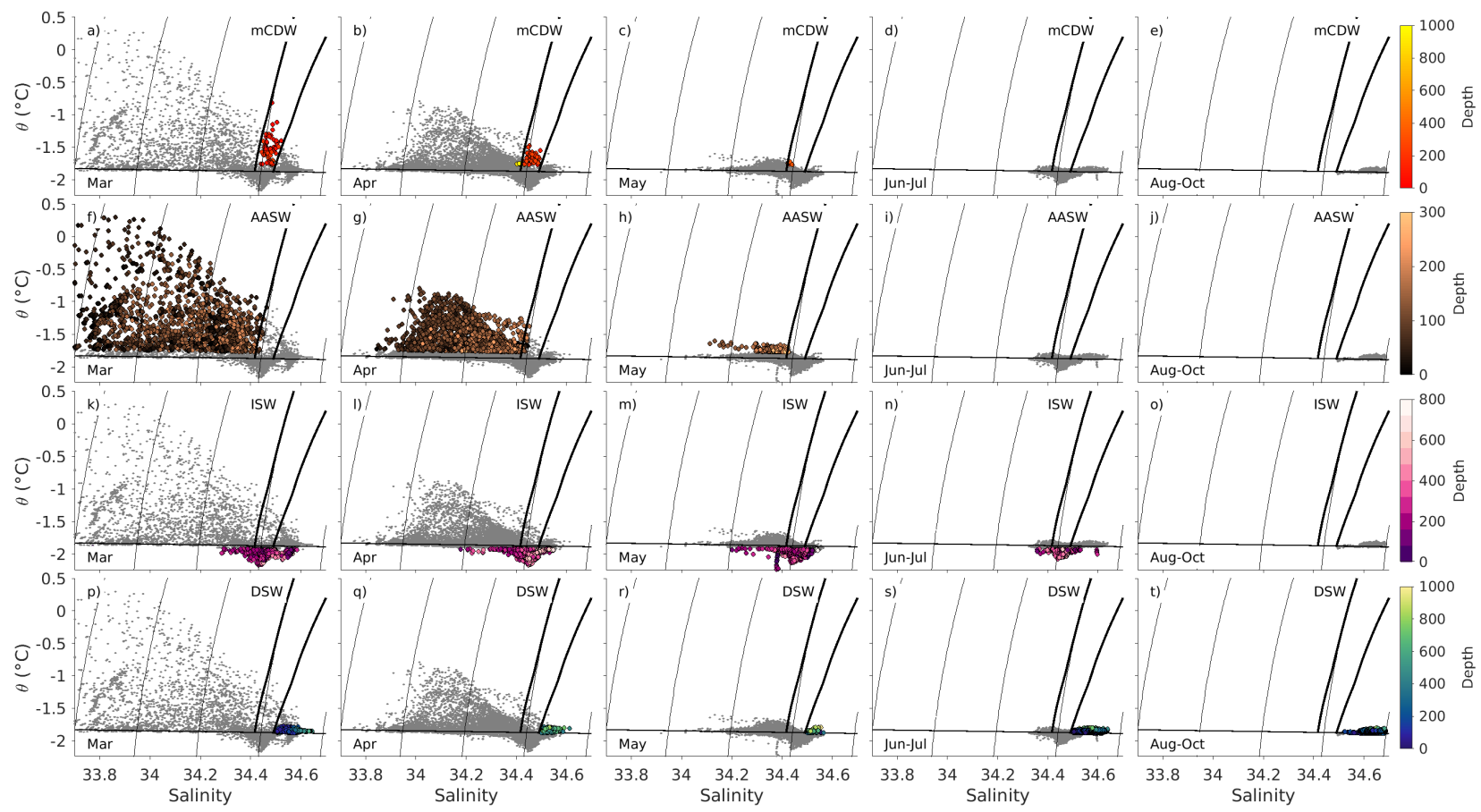

Figure 4. Seasonal T-S diagrams within the MP. The major water masses are highlighted in each row (a-e) mCDW, (f-j) AASW, (k-o) ISW and (p-t) DSW. The gray dots show all the data samples; colours (for depth) are confined to each specific water mass. The temporal evolution follows Figure 3 as March (first column), April (second column), May (third column), June-July (Fourth column) and August-October (last column). The thin contours represent the potential density, and the thick contours show the isolines of neutral density defining mCDW $(28<\gamma<28.27$ $\mathrm{kg} \mathrm{m}^{-1}$ ). The nearly horizontal black line shows the surface freezing point. The plots comprise all data from 2009 to 2017.

year. DSW salinity decreases from March until May, when it is found in the deepest levels and it salinifies progressively through the winter (Figure $4 \mathrm{p}-\mathrm{t}$ ).

\subsubsection{Vertical distribution and transformation of water masses}

The temporal evolution of vertical profiles within the MP (Figure 5) sheds additional light on the role of the different water masses in setting the stratification of the water column and their influence on the formation and evolution of DSW. To illustrate the position and variability of each water mass in relation to depth and time, Figure 5 shows each water mass with a different color palette. To avoid overplotting, we have used the daily average of all data available each year within the MP. This means extreme events might be smoothed and that we are not accounting here for the spatial variability inside the MP, which will be accounted for in the next section.

Although the length of the available seal records differs between 2011, 2012 and 2013 (the best sampled years), the structure of the water column is quite consistent between the end of March and mid June over the three years, which suggests that the seasonal variability is larger than the interannual variability in MP. However, the timing of key events like the beginning of full convection and thus, deepening of the mixed layer, differs slightly between years. Full convection begins around mid-June in 2012 (Figure 5c). In 2013 an isolated episode of full convection occurs towards the end of May when DSW is detected (Figure 5e) 

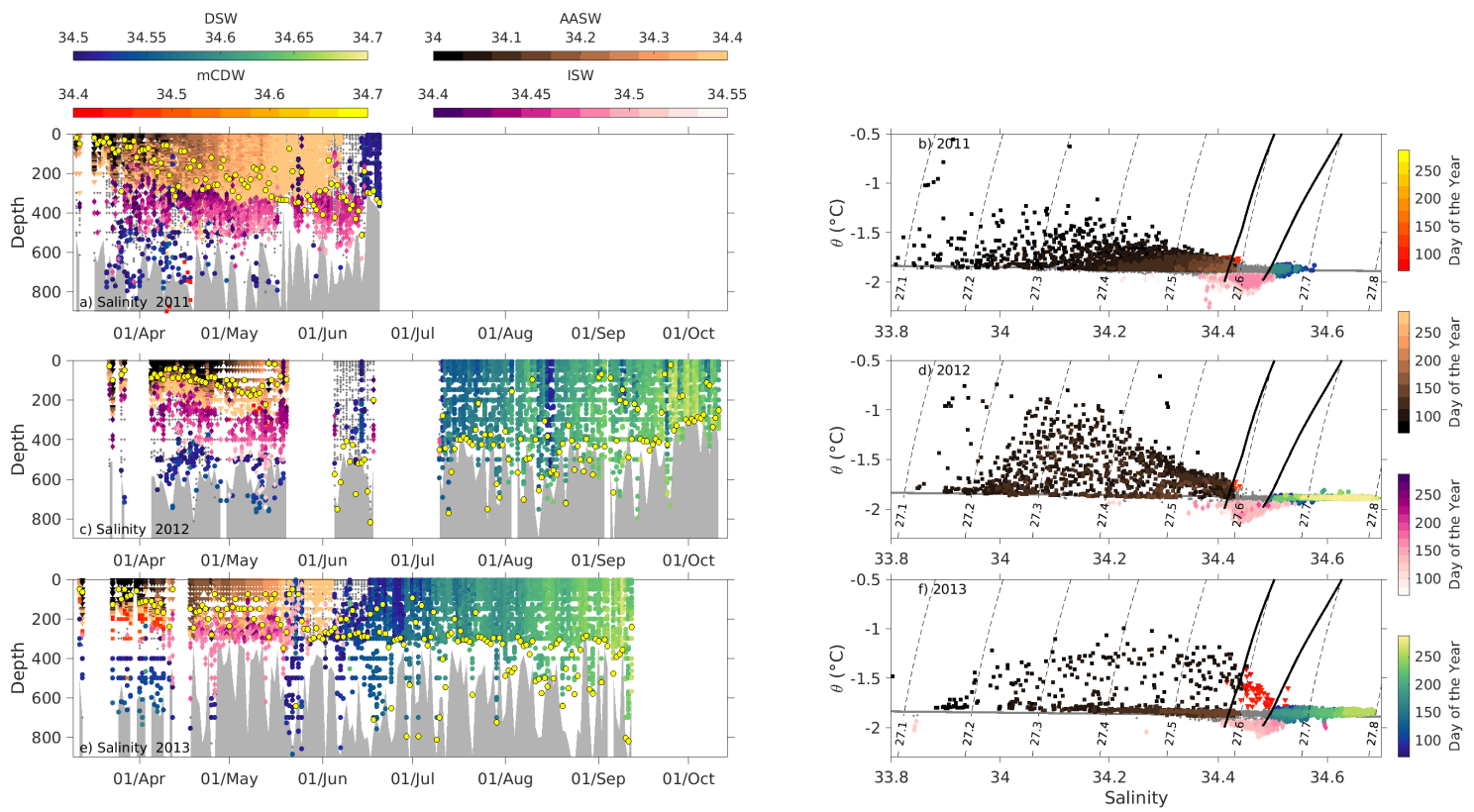

Figure 5. (a,c,e) Time series showing the vertical distribution of water column salinity in MP for the three best sampled years a) 2011, c) 2012 and d) 2013. For clarity, each water mass is shown with a different color palette. Grey dots represent the transitional water masses before the minimum DSW salinity is reached at a temperature near the freezing point (sometimes defined as Low Salinity Shelf Water (LSSW) (Gordon \& Tchernia, 1972)). The bathymetry is shaded in grey and shows the value obtained from the deepest profile among those within the daily average. The yellow dots represent the mixed layer depth as computed with a $\Delta \sigma$ criterion of $0.03 \mathrm{~kg} \mathrm{~m}$ -3 . (b, d, f) T-S diagram for MP that corresponds with panels (a, c and e) with the color palette indicating the day of the year for each water mass. The thicker black lines represent the neutral density surfaces delimiting mCDW as in Figure 4.

but after this, full convection is not achieved again until the end of June. Even though the record for 2011 is shorter than for other years, we also see the beginning of full convection in mid-June (Figure 5a). Note that Figure 5 represents an average of all measurements taken on the same day. This means that extreme events might be smoothed and that we are not accounting for spatial variability inside MP. The differences between the three years may also reflect differences in spatial sampling as discussed below. Results obtained by using every individual profile are very similar to the ones shown here.

The mixed layer depth (MLD) (yellow dots in Figure 5a, c, e) is very shallow in March $(<50 \mathrm{~m})$ when the strong stratification is set by the presence of fresh AASW at the surface with a salinity $<34$. AASW cools and salinifies with time as the result of atmospheric cooling, brine rejection, and mixing with the underlying waters as the mixed layer deepens. In May, the mixed layer base lies at the interface of AASW and ISW. Between March and the beginning of June, DSW is found in the bottom layer. This is a relatively fresh variety of DSW that is likely a remnant of DSW formed during the previous winter. As seen in Figure 4(p,q,r), the DSW in MP freshens from March to May, which suggests that this remnant DSW might be eroded via mixing with the overlying mCDW or ISW.

Around early/mid June (depending on the year), convection extends to the sea floor, and newly-formed DSW is observed over the full water column. Full-depth convection and progressive salinification of the entire water column is observed until early October in 2012 
(the end of the longest time series). mCDW is only observed in March-April of 2013, when it is directly below the mixed layer, and is mixed away when convection begins. This is in line with the horizontal distribution of the mCDW described in Figure 3.

The T-S diagrams in Figure $5(\mathrm{~b}, \mathrm{~d}, \mathrm{f})$ show the temporal evolution of each water mass and illustrate their transformation. DSW formation entails the transformation of several water masses that converge towards DSW properties. First, AASW cools due to heat loss to the atmosphere and salinifies due to brine rejection during sea-ice formation. Once the AASW density reaches that of ISW, they mix together. The transitional waters, near the surface freezing point but with salinity lower than 34.5, are shown in grey dots in Figure 5. In the literature, these waters have sometimes been referred to as Low Salinity Shelf Water (LSSW) (Nunes Vaz \& Lennon, 1996; Orsi \& Wiederwohl, 2009). Continued sea ice formation and associated brine rejection, and convective mixing increases the salinity of the water column to form DSW (salinity $>34.5$ ). These processes progressively increase DSW salinity until October. Due to the lack of data after this period, it is not possible to determine when DSW formation stops, or when the maximum DSW salinity is reached in MP. However, satellite images and several studies ((Tamura et al., 2016; Nihashi \& Ohshima, 2015; Xu et al., 2017)) suggest that October marks the end of the freezing period. At some point between mid-October and March, summer warming and freshening from sea ice melt acts to re-form a buoyant AASW surface layer. The AASW re-establishes strong stratification in the upper ocean at the start of the following warming season and isolates remnant DSW from the atmosphere.

\subsection{Spatial variability within MacKenzie Polynya}

Besides the seasonal evolution of the different water masses in MP, we are also interested in the spatial variability inside the polynya. Despite the unpredictable nature of seal sampling, we were able to compare water properties sampled by two different seals (seal 19062 and seal 19818) in two different areas within the MP between April and June of 2011.

Figure 6 shows the sampling by seal 19062 mainly in the western part of MP, near the coast (Figure 6d). This seal first travels from east to west and reaches the western side of MP around day 110 (mid April). Then, it stays within this region until the end of June (time series end). The bathymetry in this region (grey shading in Figure 6a, b) shows a fairly constant depth of $\approx 300 \mathrm{~m}$ from day 110 (mid April) over the whole period. This relatively shallow depth is one of the main particularities of this western region, and it plays a key role in the water mass distribution and transformation.

Once the seal reaches the western side of MP, near the coast around day 115, full convection is achieved. This is evidenced by the depth of the mixed layer that reaches the shallow seafloor and by the homogeneous temperature and salinity over the vertical (Figure 6b). After day 110 temperature remains approximately constant between -1.85 and -1.9 ${ }^{\circ} \mathrm{C}$ (Figure 6a, c). However, salinity increases progressively over time (Figure 6b, c). This densification of the water column within the shallow northwestern MP is well represented in the T-S plot (Figure 6c) and reveals the progressive salinification and formation of new DSW from around mid-June ( $\approx$ day 165 ).

Despite the relatively small size of the MP (between 1800 and $6000 \mathrm{~km}^{2}$ (Tamura et al., 2008)), we observe large spatial variability in the water-mass distribution around the same period of the same year. A second seal, seal 19818, offers another view of DSW formation in the eastern MP from April (day of year 110) onward (Figure 7). This seal first travels northwestward and offshore towards the eastern side of Cape Darnley polynya and then southward back to the eastern MP where it spends most of the time. Here, close to the Amery ice shelf calving front, ISW is observed below relatively warm AASW $\left(\theta<-1.6^{\circ} \mathrm{C}\right)$, at depths ranging from $\approx 300$ to $600 \mathrm{~m}$ depth. Its potential temperature ranges from $-2.1^{\circ} \mathrm{C}$ to $\approx-1.95^{\circ} \mathrm{C}$ and its salinity from 34.4 to more than 34.5 (Figure $7, \mathrm{a}-\mathrm{c}$ ). As the winter draws on, the mixed layer salinity increases and the MLD deepens. However, in contrast 

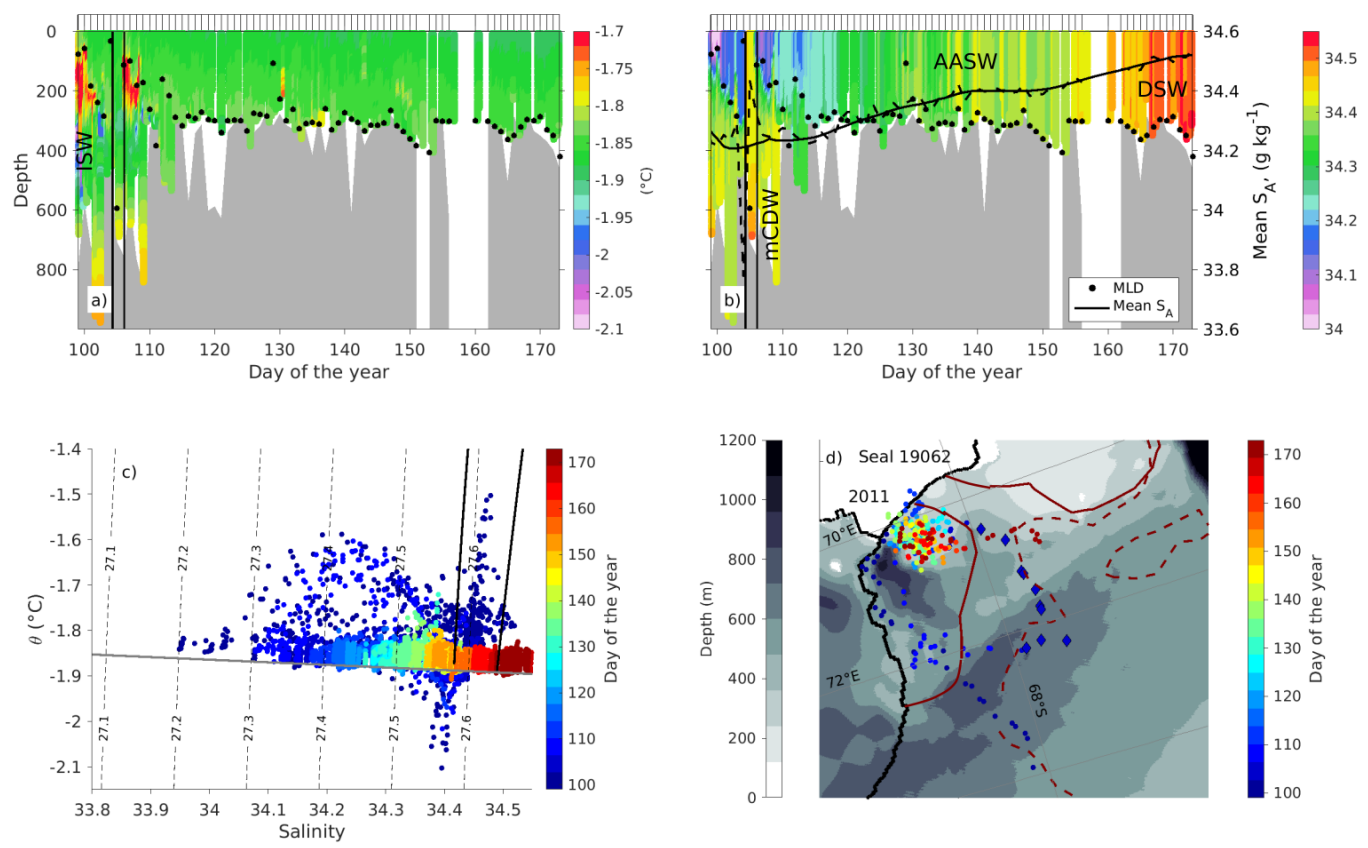

Figure 6. Data in 2011 as sampled by seal 19062. (a, b) Time series of (a) potential temperature and (b) salinity inside MP. The dashed line in panel (b) represents the daily mean salinity over the top $300 \mathrm{~m}$ of the water column while the solid line is the 8-day running mean salinity. Vertical lines in (a) and (b) highlight a period of anomalously high salinity. Black vertical lines at the top show the daily intervals used to calculate daily salinity means over the top $300 \mathrm{~m}$. (c) T-S diagram colour-coded with day of year. (d) Map showing the bathymetry and the position of the seal sampling colour-coded by day of year. The diamonds correspond with the periods of anomalously high salinity in (b). The dashed brown line in (d) shows the polynya extent at the beginning of the sampled period (April) and the solid brown line is the equivalent for the end of the period (June).

to the western MP, the stratification set at the interface of the AASW-ISW hinders full convection and hence DSW formation.

As shown in this section, the spatial variability inside MP is intimately related to the bathymetry and its influence on the circulation and water-mass distribution in the water column. The shallower bathymetry of the western MP restricts inflow of ISW, which results in weaker stratification there. Therefore, DSW is formed more efficiently and quickly at this shallow location.

In addition to the spatial variability inside MP, the sampling of seal 19818 shows other striking features. Events of anomalously high salinity have been highlighted between two successive vertical black lines in the salinity section (Figure $7 \mathrm{~b}$ ). These profiles are represented by diamond symbols in the map (Figure $7 \mathrm{~d}$ ). The region north of MP and east of Darnley polynya exhibits relatively high salinity, and temperatures near the surface freezing point (i.e., LSSW/DSW) over the whole water column. It is surprising to find these properties outside of the active polynyas, where the saltiest DSW is produced. Possible explanations include: (i) local convection during brief periods when strong winds remove sea ice from the region (X. Wang et al., 2021), (ii) DSW formed in MP and exported through this region towards the open ocean, and (iii) advection of relatively salty and cold water formed in a different location. 

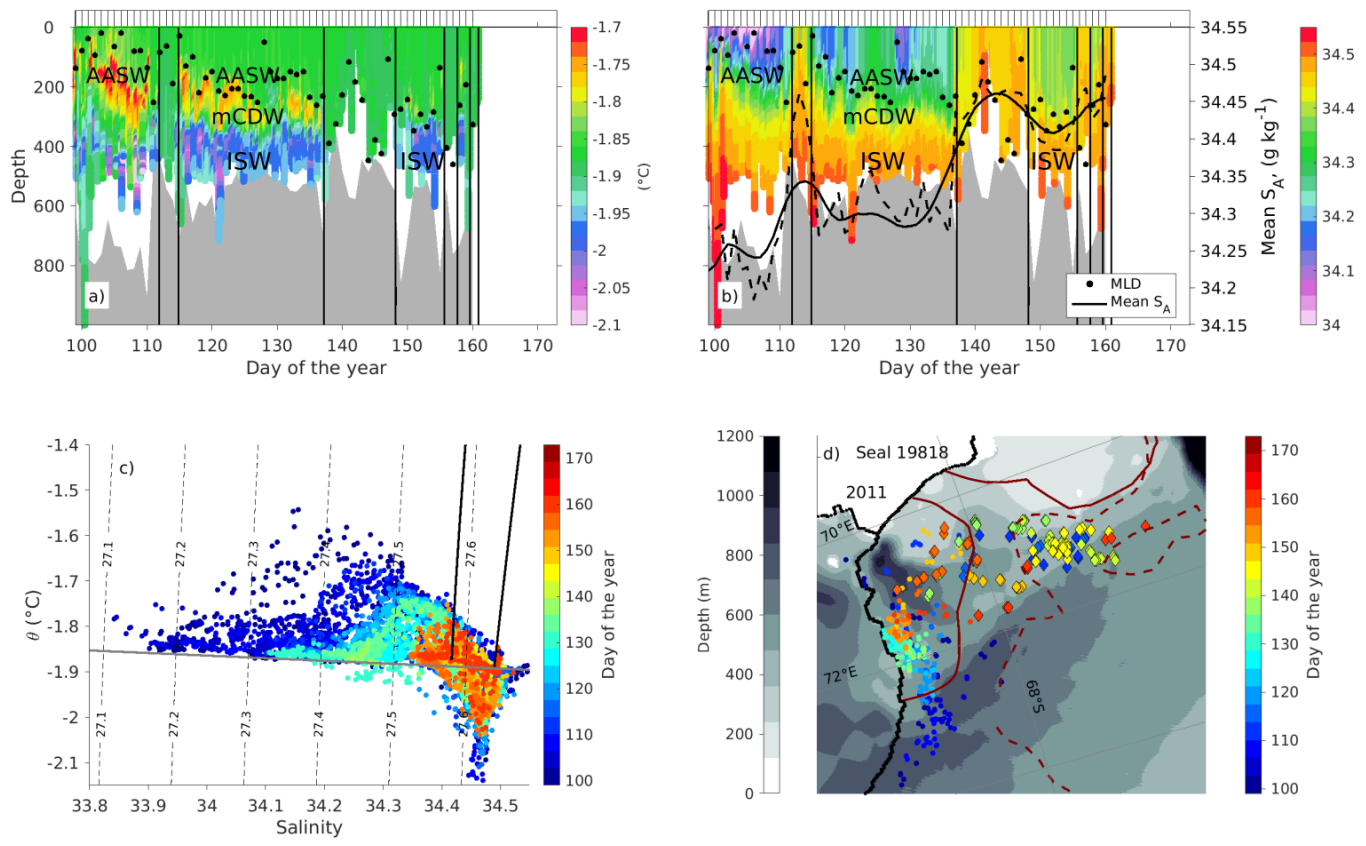

Figure 7. Same presentation as Figure 6 but for seal 19818 sampling between April and June in 2011. The axes are the same for both figures in order to facilitate the spatial and temporal comparison.

The first hypothesis would explain the episodic salinity increase and the appearance of salty water outside of MP; however, it would be accompanied by an increase of salinity within the polynya too. Exploratory analyses from wind data, showed no correlation between wind velocity and the mentioned features (not shown). Further analysis of MODIS sea ice imagery (corrected reflectance, https://worldview.earthdata.nasa.gov) shows that the region of high-salinity profiles is almost completely ice-covered before and after the time of the measurements (Figure S2). Episodic convection is unlikely in a sea-ice covered region. Unfortunately, there is a data gap between May and August 2011 that prevents a more definitive assessment of this hypothesis.

To shed more light on the possible origin and pathways of this anomalous high salinity water (i.e., LSSW) and test the second and third hypotheses, we compared seal profiles collected between days 125 and 148 in three different regions: the shallow western region of MP, the region of high salinity north of MP, and the northern edge of Darnley polynya (Figure 8 ). This period spans the dates when one of these episodes is observed $(\approx$ days 137-148, Figure 7b).

The salinity and T-S properties at the three locations show distinct features. In the shallow western region of MP, full convection and progressive salinification is observed. However, at this early stage, DSW salinity is not yet achieved and the saltiest water observed is LSSW. Figure 6 shows DSW observed later in the year. The high salinity event observed further north is therefore unlikely to originate from MP as, at the same time of year, water inside MP (Figure $8 \mathrm{a}$ ) is significantly fresher (maximum of $\approx 34.43$, Figure $8 \mathrm{~b}$ ) than water found north of MP $(\approx 34.5)$ (Figure 8c, f).

Data collected within the MP prior to the high salinity event (grey lines and dots in Figure 8e, f) also show fresh waters with strong influence of ISW and absence of full convection. This provides further evidence that the high salinity water found further north 

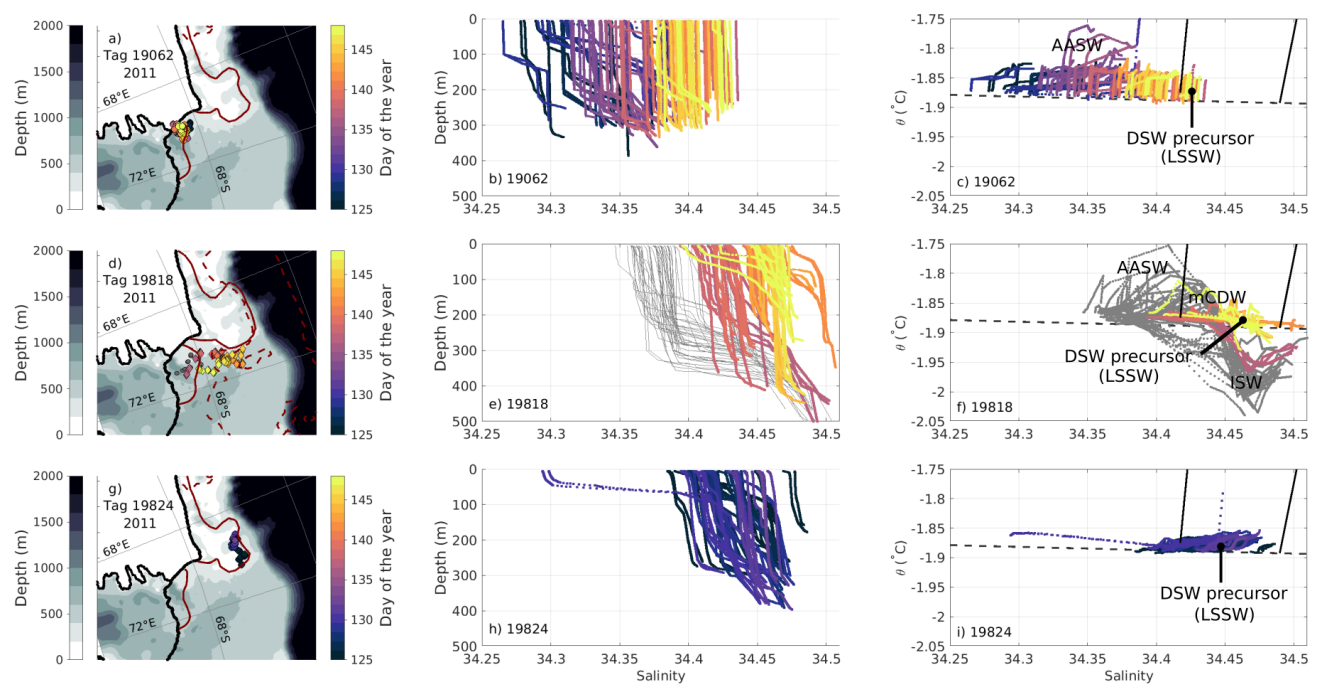

Figure 8. The evolution of the temperature and salinity properties in three regions to provide more insight into the origin of the anomalous high salinity water. (a, d, g) Location, (b, e, h) salinity profiles and (c, f, i) temperature-salinity diagrams between days of the year 125 and 148 in three different regions: the shallow area in southwest MP (a-c), the area of anomalous high salinity to the north of MP shown in Figure 7 and (d-f) in the northeastern edge of Darnley polynya (g-i). The grey dots in panels (d-f) show the water-mass properties before the period represented in color, to help compare conditions inside and outside the MP.

is not sourced from MP. On the other hand, salinity at the edge of Darnley polynya is by day 130 already almost as high as the high salinity events observed west to the Prydz Channel between days 135 and 148 (Figure 8h, i). While there are no data available in these two regions at the exact same dates, the presence of cold and relatively salty water with similar properties in the two locations suggests that the Darnley Polynya may be the source of the high salinity events observed in the Prydz Channel.

The hypothesis raised here is then that, due to the shallow nature of the eastern Darnley polynya, full-depth convection and salinification of the water column occur earlier in the year than in MP. The high-salinity events might therefore reflect DSW formed in Darnley polynya that drains eastwards into Prydz Bay. Later in the year, when full convection and DSW formation is also achieved in MP, MP contributes DSW that is exported through Prydz Channel. This explanation, while hypothetical, is consistent with the available observations.

\subsection{Export pathways}

DSW formed in MP and other polynyas is exported offshore to supply AABW. However, due to the limited sampling in these regions, the export pathways are poorly known. In the absence of velocity data, we investigated whether the water properties provided any insight into DSW export pathways. To do so, we have split this water mass into two categories, based on its position in the water column: (i) DSW present in bottom layers (bottom of the dive DSW, Figure 9a-d) and, (ii) DSW present within the mixed layer (the maximum salinity of DSW within the mixed layer, (Figure 9a-d)). If DSW is present in both the surface and bottom layers, this is an indication that full-depth convection is underway and new DSW is locally formed. It has been observed that the seals often dove to (or near) the seafloor (Figures 5, 6, 7 and 11), so the bottom-of-the-dive salinity is usually a good approximation of the salinity at the bottom of the water column. 
As can be seen in Figure 9, new DSW is mostly formed within the polynyas. When DSW is observed in the bottom layer but is absent in the mixed layer outside the polynyas, it could not have been produced by local convection and must therefore have been transported to that location. In other words, the presence of DSW unconnected to local convection reveals DSW export pathways towards the open ocean. This bottom water is mainly observed in late summer until May, so in addition to being exported, part of this DSW could be stagnating at some point and being mixed with overlaying waters over time. Such mixing could be enhanced by the intermittent inflow of mCDW onto the shelf (C. Liu et al., 2018). In polynyas, if DSW is present near the bottom and absent in the mixed layer, this suggests that the DSW is a remnant of DSW locally formed during the previous winter, while the upper water column has freshened and transformed during summer ice melting. Note that the polynya boundaries shown in Figure 9 are only indicative as they represent the mean value over the given period.
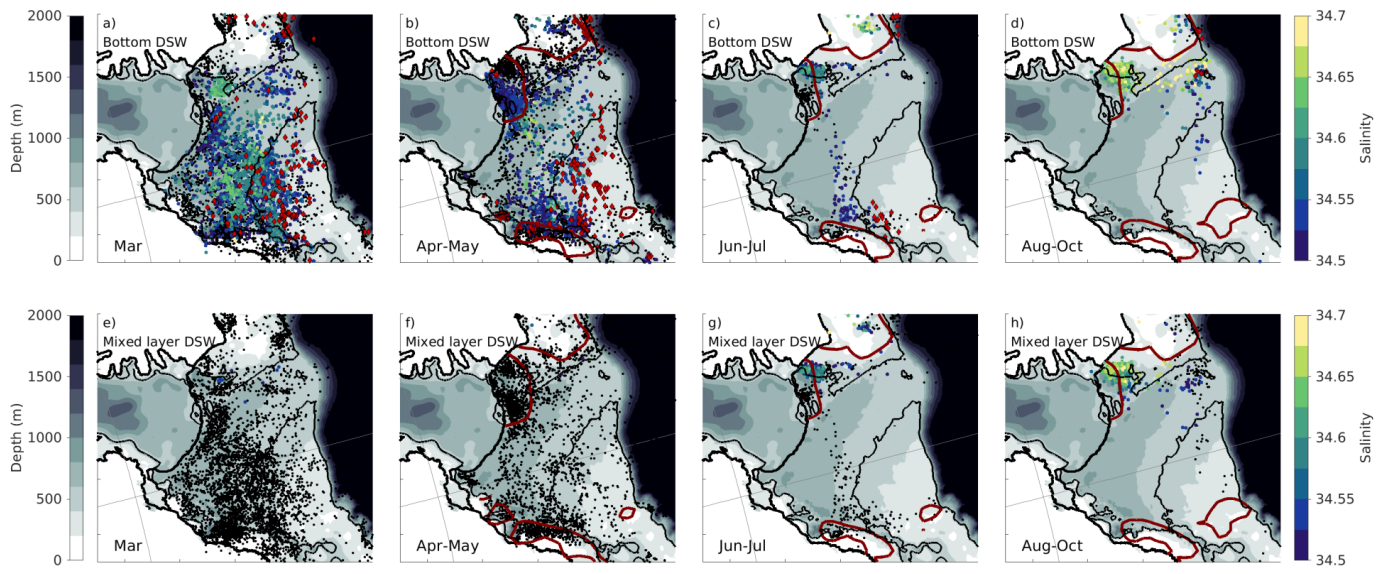

Figure 9. (a-e) Bottom-of-the-dive salinity and (f-j) maximum salinity within the mixed layer in Prydz Bay. Black dots represent all profiles with no DSW present. The brown contours delimit the polynyas and the black contours represent the $500 \mathrm{~m}$ depth bathymetry to illustrate the Prydz Bay channel. Red diamonds represent the mSW.

The main export pathway of DSW from the polynyas is towards the Prydz Channel, in agreement with (Williams et al., 2016). This is best observed from March to May before new DSW is formed and the saltiest bottom DSW is present (Figure 9a-b). Only in March, when the bay is mostly ice-free, is relatively fresh DSW also found to the east of the channel, on the Four Ladies Bank. This is consistent with saltier (denser) waters occupying the deepest layers of the water column (i.e cascading and being exported along the Prydz Channel). This is consistent with the presence of $\mathrm{mSW}$ (red diamonds), resulting from the mixing between DSW and mCDW, to the east of the channel and around Davis and Darnley polynyas. The fresher nature of bottom DSW in eastern Prydz Bay could be explained by two different mechanisms: (i) it might reflect the mixing of DSW with mCDW, which is fresher than the DSW and is ubiquitous in this region or, (ii) it could be due to the fresher nature of the DSW formed in the eastern Prydz Bay polynyas: Davis and Barrier (Williams et al., 2016). When new DSW starts forming in MP in June-July, (Figure 9g), salinity increases over the whole water column and the remnant DSW is no longer evident.

Williams et al. (2016) speculated that some of the DSW formed in MP flowed from Prydz Channel to the Darnley Polynya, beneath the Cape Darnley ice barrier (Williams 
et al., 2016). They hypothesized this inflow of relatively dense water might pre-condition the Cape Darnley polynya and boost the production of DSW there. Based on the timing and salinity of high salinity events observed in Prydz Channel, we conclude it is more likely that some DSW formed in Cape Darnley flows eastward into the Prydz Channel. DSW is not found at the bottom in the shallow region between the polynyas from March to May (see black dots in Figure 9a, b). It seems more likely that new DSW formed in the shallow region in the western MP in winter (June-July) drains offshore along the Prydz Channel (Figure 9d, h) and no DSW remains to the next winter in this shallow part of the MP. More complete observations of water properties, current flow and bathymetry are needed to conclusively resolve this issue.

The seasonal distribution of the DSW properties has provided new insight on the likely DSW export pathways, as summarized in Figure 10. The main DSW export pathways proposed here are (i) From Prydz Bay polynyas to the Prydz Channel, (ii) from Darnley directly to the shelf break and further offshore, and (iii) from Darnley polynya into the Prydz Bay beneath or around the fast ice. While the pathways inferred here are consistent with the observations analysed in this and (except for (iii)) in previous studies (e.g., Williams et al. (2016), Ohshima et al. (2013)), they remain hypothetical until confirmed with additional observations.

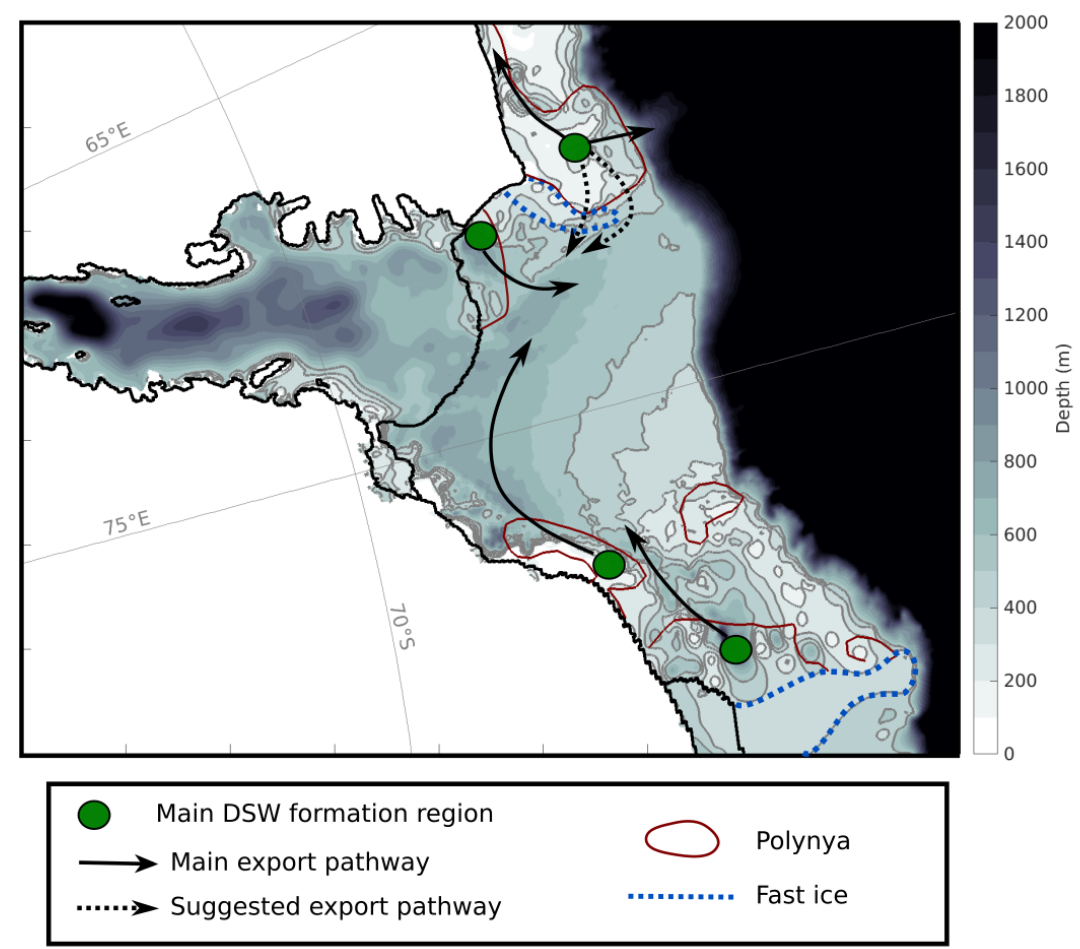

Figure 10. Schematic of DSW export pathways (black arrows) inferred from the seasonal properties and distribution of DSW and from previous studies (Ohshima et al., 2013; Williams et al., 2016). The main features are indicated in the legend.

\subsection{Dense Shelf Water transformation in Mackenzie Polynya}

The sampling by a single seal in 2013 (Figure 11) provides a complete time series from March to October in MP. This seal sampled the eastern side of the polynya in March, then it traveled to the western side and stayed there until October. This long record provides 

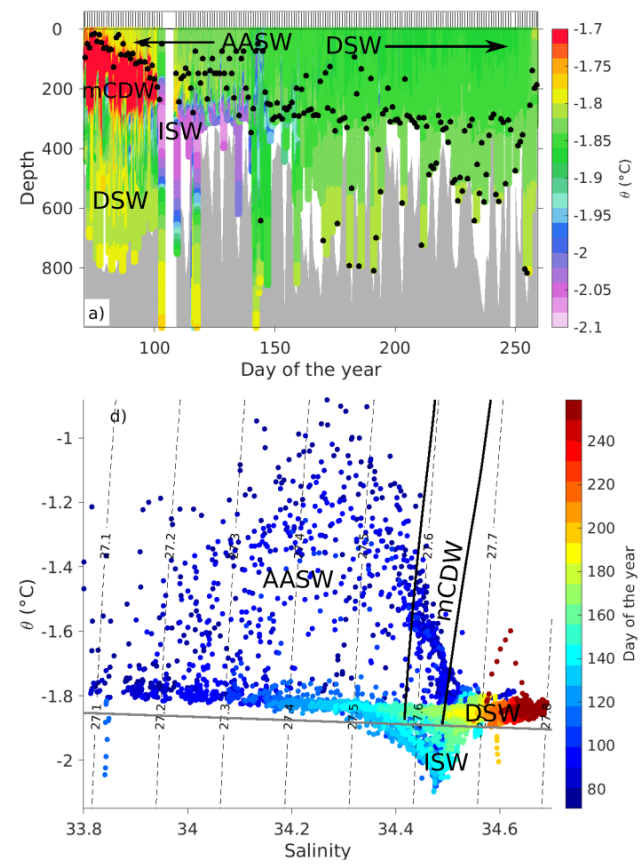
inside MP.
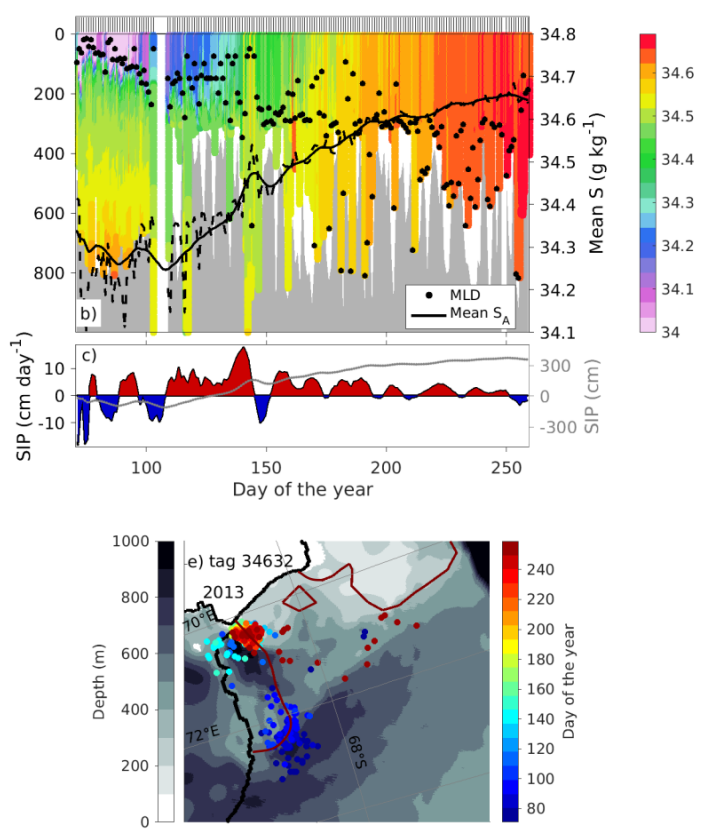

Figure 11. Time series of (a) potential temperature, (b) salinity, and (c) SIP (rate and cumulative) inside MP during 2013. Mean salinity over the top $300 \mathrm{~m}$ of the water column and the 8-days running mean salinity over the top $300 \mathrm{~m}$ of the water column are depicted by the dashed and solid lines, respectively. (d) T-S diagram color-coded by the day of year. (e) Maps showing the relative position of the seal sampling and the bathymetry. The brown contours show the polynya delimitation. Black vertical lines at the top of $\mathrm{a}$ and $\mathrm{b}$ axes show the daily intervals used to calculate daily salinity means over the top $300 \mathrm{~m}$.

valuable information on the time evolution of the salinity and the mixed layer at this location. Because the seal sampled a narrow area, the time series also allows a rough estimate of SIP

From March to mid-April (around day 100), the eastern MP is dominated by the presence of AASW. Very fresh waters $(\mathrm{S}<34)$ occupy the mixed layer, and some warm and relatively salty mCDW $(\mathrm{S}>34.4)$ is found just beneath (Figure 11a, b). This contrast in water properties results in strong stratification. The mixed layer depth increases from $<50$ $\mathrm{m}$ in March (day 80) to $200 \mathrm{~m}$ depth 20 days later. However, the deepening of the mixed layer between days 80 and 100 coincides with the time when the seal moved from the eastern to the western side of the polynya (Figure 11e), so spatial variability may have contributed to the stratification change.

In contrast to year 2011 shown in Figure 7, ISW is absent in eastern MP. This might be due to interannual variability of the mCDW inflow, stronger in 2013. This is consistent with the abrupt decrease of $\mathrm{mCDW}$ temperature below $\approx 300 \mathrm{~m}$ depth that might reflect the mixing of the inflowing mCDW with the outflowing ISW, usually observed at this location (Figure 7) (Herraiz-Borreguero et al., 2016; Williams et al., 2016). The rapid change in seal location is accompanied by a large change in the structure of the water column. In the western MP, the upper water column is still occupied by AASW that gets progressively saltier from $\approx$ day 110 . ISW, absent at the eastern edge of MP, is now present below the mixed layer, between $\approx 250$ and $600 \mathrm{~m}$ depth. This reveals the strong spatial variability of the ISW distribution along the ice shelf calving front. 
As the winter draws on, convective mixing due to atmospheric cooling and brine rejection progressively erodes the pycnocline. This results in mixing of ISW with water in the mixed layer, and in the formation and progressive densification of DSW. From the end of June ( $\approx$ day 180 ), the convective mixing reaches the seafloor. MLD can reach depths of up to $800 \mathrm{~m}$ during this period. Abrupt changes in the bathymetry, reflecting the seal navigation within the MP, translate into large variations in the MLD. The sustained salinity increase in the western MP between April and September (Figure 11c) implies fairly continuous sea ice formation during this period. Towards the end of September $(\approx$ day 220$)$ and until the end of October (the end of the time series) the mean salinity remains approximately constant, and the SIP estimate approaches zero (Figure 11c). To test the sensitivity of the SIP computation to the reference depth and to the presence of ISW, we have performed a test of SIP using a different criterion (Figure S1). SIP with a reference depth for mean salinity of $100 \mathrm{~m}$ provides similar relative values but with lower daily rates. However, in this particular region and year, $300 \mathrm{~m}$ approximates the average depth of the mixed layer once convection is achieved. In most of the sampling period, the bottom-of-the-dive depth reaches around $300 \mathrm{~m}$. In contrast, the $100 \mathrm{~m}$ reference will only suit the first part of the sampling period (until the beginning of April), when sea ice formation just started.

To illustrate the seasonal evolution of the DSW properties within the MP between 2011 and 2013, we have computed the maximum salinity of the DSW (when present) over the whole water column and the corresponding temperature (Figure 12). This means that the depth range of the DSW varies seasonally: in winter, DSW will be found within the mixed layer, where its salinity is mostly homogeneous, and in late summer, DSW is found mainly in bottom layers, as a remnant from the previous winter. This is comparable with previous studies on DSW properties that used bottom-of-the-dive salinity (e.g., Williams et al. (2016) and,Ohshima et al. (2013)).

For the analyses in Figure 12, we have used the daily average of all data available in the polynya. This means that we are not accounting here for the spatial variability already described above. DSW properties computed using every individual profile are similar, but noisier (not shown).

Little interannual variability is observed in the DSW properties, except for the temperature in 2013 , which is up to $0.05{ }^{\circ} \mathrm{C}$ higher from July to October. This figure clearly shows the evolution of DSW salinity: it is nearly constant until the beginning of June (with absolute minimum values in 2011 between April and May) and then increases quickly (Figure 12a) to finally stabilize by the end of September. However, while salinity evolves in two steps (before and after the beginning of June), the MLD deepens smoothly until the beginning of September, when the water column begins to re-stratify (Figure 12c). This is in agreement with the stabilization of the salinity increase (Figure 12a) and, therefore, of the cumulative SIP (Figure 11c). The starting point for salinity increase at the beginning of June coincides with the time when the MLD reaches $300 \mathrm{~m}$ (at least in 2011 and 2013) and progressively erodes the underlying ISW. This suggests that this is the moment when newly formed, mixed layer DSW becomes saltier than the remnant found in the bottom.

The temperature of the saltiest DSW (Figure 12b) is nearly constant over the whole record, except for the period between April and May. Over these two months, DSW temperature drops below the surface freezing point at the same time that DSW reaches its minimum salinity. This suggests that the deep outflow of ISW in April and May might be freshening and cooling the remnant DSW from the last winter. Also, this cold DSW has the same temperature as the warmer ISW as defined in Table 1; this means that we might be observing a combination of fresh and cold variety of DSW and a warm and salty type of ISW over this period. What happens between October and April is uncertain, as we have little summer data, but one hypothesis is that the dense DSW formed in winter flows offshore and is replaced by lighter water. 

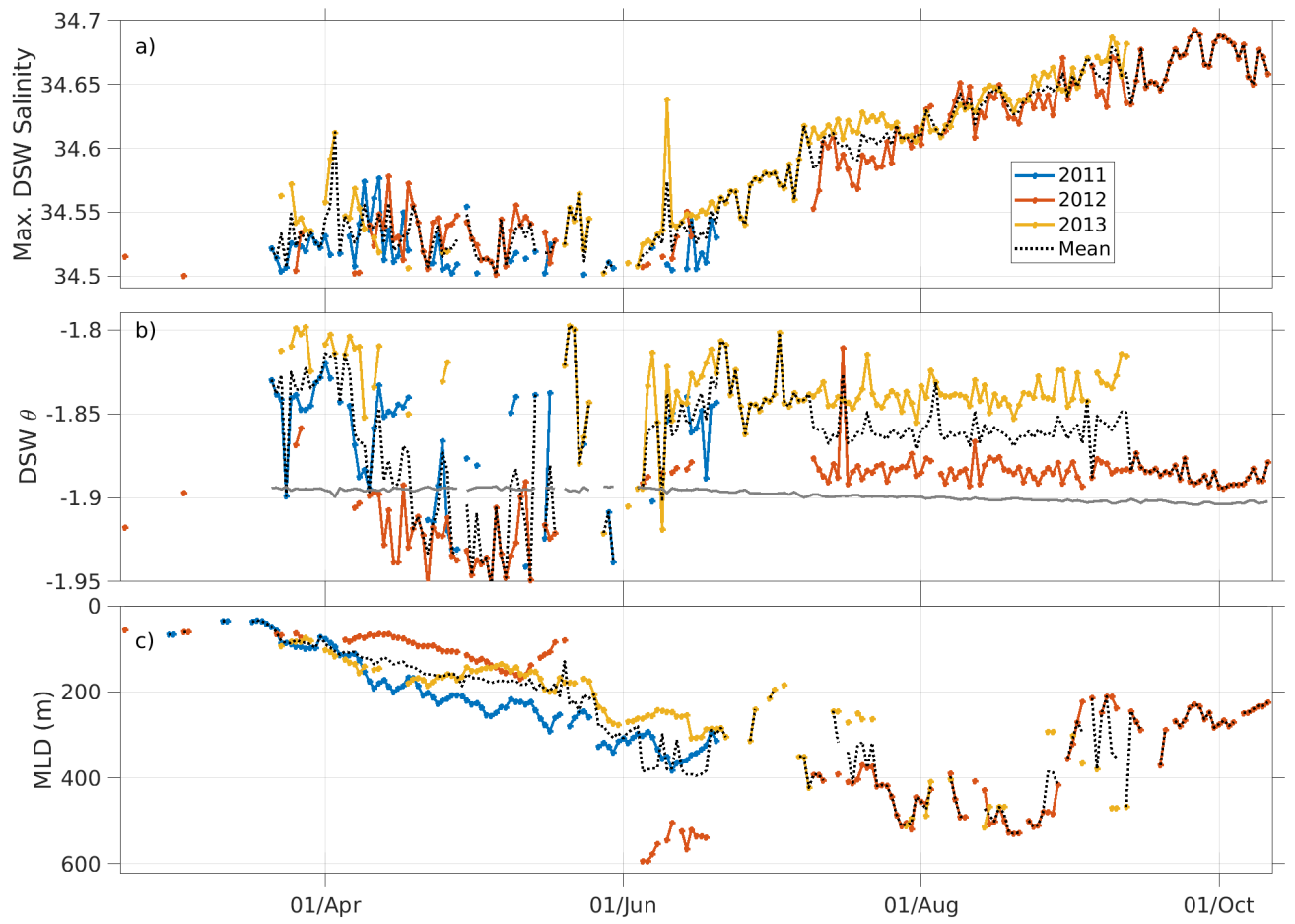

Figure 12. Time series of (a) maximum DSW salinity over the water column, (b) potential temperature at maximum DSW salinity, and (c) MLD for the three best-sampled years in MP (2011, 2012, 2013). The grey line in panel (b) shows the surface freezing point.

\section{Discussion}

Within Prydz Bay, the presence and spatial variability of the different water masses reflect regional ocean dynamics, the proximity of the Amery ice shelf, the topography, and the presence of the four polynyas. In addition, the water-mass transformations over the seasonal cycle strongly depend on their mutual interactions.

The main ISW outflow in Prydz Bay has been observed in and around MP (HerraizBorreguero et al., 2015; Williams et al., 2016; Xu et al., 2017), at the western side of the Amery ice shelf calving front. In the rest of the bay, the presence of ISW reduces as the winter progresses. We argue that this is likely due to isopycnal mixing between the ISW and mCDW, ubiquitous in central and eastern Prydz Bay, since both water masses share a similar depth and density range in this region (Figure 11). In contrast, the continued outflow of ISW within the MP might (i) act as a barrier that prevents the spreading of mCDW into this region or (ii) dilute any signal of $\mathrm{mCDW}$ reaching the western MP. The presence of strong fronts near the ice shelf calving front due to the outflow of ISW in the west and the inflow of mCDW in the east has been noted by C. Liu et al. (2018). In the absence of significant amounts of $\mathrm{mCDW}$ in western MP, the seasonal water-mass transformation is strongly conditioned by the presence of ISW, which in turn depends on other factors such as bathymetry (ISW is found below $200 \mathrm{~m}$ depth and its core is around $300 \mathrm{~m}$ depth, and so it barely reaches the region of shallow bathymetry in western MP) or the proximity of the ice shelf. While AASW, which maintains strong stratification of the water column until late summer, undergoes seasonal transformation by atmospheric cooling and brine rejection, the stratification set from underneath by ISW is only removed by intense convective mixing. The hydrographic data used in this study have limited spatial and temporal resolution, 
therefore we cannot dismiss the possibility that intermittent inflow of mCDW (e.g., C. Liu et al. (2018)) might cause ice melt and contribute to the presence of ISW in the eastern side of the MP. However, the western MP would be too shallow to receive the out-flowing ISW.

The water-mass distribution in MP generally agrees with that reported in previous studies (Herraiz-Borreguero et al., 2016; Ohshima et al., 2013; Williams et al., 2016; Xu et al., 2017) while our results provide new insight on the seasonal and spatial variability within the MP. The spatial variability is linked to the varying topography, which influences DSW formation in three ways: (i) when full convection is achieved, a shallower water column experiences quicker salinity increase under brine rejection (i.e., for a given input of brine, the salinity increase will be larger for a smaller volume/shallower water column). This results in saltier and more rapidly formed variety of DSW. As a consequence, (ii) full convection is achieved earlier in the year in shallow regions. In addition, (iii) the shallower topography $(<300 \mathrm{~m}$ depth) limits the presence of ISW, which is usually found at deeper levels. The absence of ISW potentially results in less stratified waters than when it is present. Freshwater input from basal melt of ice shelves partially offsets the salt flux by sea ice formation in polynyas, increasing stratification and inhibiting full-depth convection and formation of DSW (Herraiz-Borreguero et al., 2016; Williams et al., 2016; Silvano et al., 2018; Hellmer, 2004). We found here that MP can be divided into two different regimes: a shallow area ( $<300 \mathrm{~m}$ depth) in the west where, in the absence of ISW, full convection and DSW formation begin early in the year; and deeper waters further east where the presence of AASW and ISW results in stronger stratification. This delays the onset of deep convection and results in the formation of fresher, lighter DSW.

It has been suggested (Williams et al., 2016) that the DSW formed in Prydz Bay follows two export pathways. Consistent with earlier work, we found that the saltiest (and densest) type of DSW is exported offshore from Prydz Bay through the Prydz Channel, the main export pathway. Ohshima et al. (2013) have inferred from bottom salinity measurements that the salty waters on the slope and in the open ocean are exported DSW. Based on the most recent water-mass classification (Williams et al., 2016; Herraiz-Borreguero et al., 2016), these waters are too warm to be considered as DSW. It would be more precise to say that they represent mixing between mCDW and DSW (mSW) that, when found on the slope, constitute a precursor of AABW (Ohshima et al., 2013; A. P. Wong \& Riser, 2013). Our observations also show that $\mathrm{mSW}$ is present on the shelf, mainly in the eastern part of Prydz Bay. Its presence on the shelf reveals mixing between DSW and mCDW, which is ubiquitous in eastern Prydz Bay (Herraiz-Borreguero et al., 2015, 2016; Williams et al., 2016; C. Liu et al., 2018).

Previous studies, using part of the data set used here (only years 2011 and 2012), have suggested another export pathway for DSW from MP to the Darnley Polynya, passing below the fast ice barrier separating the two polynyas (Ohshima et al., 2013; Williams et al., 2016). With this updated data set, we do not find any clear evidence of DSW export from MP towards Darnley polynya. DSW is not found in the region between the MP and Cape Darnley polynya between February and May. The DSW found later in the season (June to October) near the coast is new DSW formed in MP. We find it more likely that the transport occurs in the opposite direction i.e., from Darnley to Mackenzie. This would be consistent with gravity-driven cascading of dense water from the shallow region of the Darnley polynya to (i) deeper locations within the polynya, (including the western part of the Darnley Polynya where very salty DSW is found near the coast (Figure 3)), (ii) to Prydz Bay following the bathymetry (see $500 \mathrm{~m}$ isobath in Figure 9), or (iii) directly downslope to the open ocean. The hypothesis that DSW cascades from Darnley to Prydz Bay would explain the anomalously high salinity observed over the whole water column in the area between Darnley and Mackenzie and the similar salinity profiles observed in this region and in the eastern Cape Darnley polynya (Figure 8). However, conclusive statements on the exchange of DSW between Cape Darnley and Prydz Channel will require additional information on the bathymetry and current velocity in the vicinity of the Cape Darnley 
Ice Barrier. Since hydrographic data only provide information on the water properties at a particular moment, it is also possible that the flow in the region reverses at different time scales.

Based on geopotential anomalies derived from hydrographic profiles in Prydz Bay, the large-scale circulation was described to be a cyclonic gyre (Smith et al., 1984; Nunes Vaz \& Lennon, 1996; Williams et al., 2016). Previous modelling studies also showed that the outflow of the Prydz Bay gyre hugs the western rim of the bay and thus favors the offshore transport of DSW from MP to the shelf break (Figure 1 (C. Liu et al., 2018; Galton-Fenzi et al., 2012; C. Liu et al., 2017). Our results suggest that in addition to this large-scale shelf circulation carrying DSW from MP to the shelf break, some DSW formed in eastern Cape Darnley polynya drains to the Prydz Trough and supplements the MP contribution. The transport of water from Darnley Polynya to Prydz Bay may be episodic and might be facilitated by tidal currents. Diurnal tidal currents have been found to exceed $0.1 \mathrm{~m} \mathrm{~s}-1$ off the point of Cape Darnley (Hemer et al., 2006). Previous studies in the Ross Sea have suggested that plume jets are shaped by tidal currents (Q. Wang et al., 2010). While tidal currents in Prydz Bay are not as strong as reported in other parts of the Antarctic continental shelf (Padman et al., 2009; Q. Wang et al., 2010), tidal oscillations could facilitate transport of DSW formed in the Darnley Polynya to Prydz Bay (see Figure 7 in Hemer et al. (2006)). While the modelling studies cited above do not reproduce the DSW transport proposed here, this could be related to the fact that they do not include tidal forcing (C. Liu et al., 2018), to the unknown bathymetry, and to insufficient spatial resolution (Galton-Fenzi et al., 2012; C. Liu et al., 2018).

The dense sampling provided by instrumented seals has revealed unanticipated spatial and temporal variability in the seasonal evolution of the stratification and water mass structure in the MP and broader Prydz Bay. This variability highlights a number of factors regulating the formation of DSW in coastal polynyas, including bathymetry, sea ice production, and meltwater input. The saltiest and densest DSW in MP is formed over the relatively shallow waters on the western side of the polynya. Shallow topography may also restrict the inflow of ISW that increases stratification and, therefore, delays the onset of fulldepth convection. Sea ice formation is clearly critical for driving the salinity and density increase resulting in the production of DSW. However, the input of glacial meltwater will tend to compensate brine released during sea ice formation (Herraiz-Borreguero et al., 2016; Williams et al., 2016; Silvano et al., 2018), reducing or preventing the formation of DSW. Because bathymetry exerts a strong influence on the circulation on the Antarctic continental shelf and on AABW formation (Mensah et al., 2021), these three factors: bathymetry, salinification by sea ice formation, and freshening by glacial meltwater (which in turn depends on ocean heat transport to ice shelf cavities), are linked and not mutually exclusive. Understanding these interactions is, therefore, key to explaining differences between the behaviour of individual coastal polynyas and their sensitivity to changes in forcing.

\section{Acknowledgments}

The seal CTD-SRDL tags and deployment were funded and supported through a collaboration between the French Polar Institute (program 109: PI. H. Weimerskirch and 1201: PI. C. Gilbert and C. Guinet), the SNO-MEMO and CNES-TOSCA and the Integrated Marine Observing System. Australia's Integrated Marine Observing System (IMOS) is enabled by the National Collaborative Research Infrastructure Strategy (NCRIS). It is operated by a consortium of institutions as an unincorporated joint venture, with the University of Tasmania as Lead Agent. www.imos.org.au. This project received grant funding from the Australian Government as part of the Antarctic Science Collaboration Initiative program. The Australian Research Council provided financial support through Discovery Projects DP180101667 and DP210103091. E.P.R is supported under ARC Discovery grant DP180101667 and S.B is supported under ARC DECRA grant DE180100828. The work was supported in part by the Centre for Southern Hemisphere Oceans Research, a partner- 
ship between CSIRO, the Qingdao National Laboratory for Marine Science and Technology, the University of New South Wales and the University of Tasmania and by the Australian Antarctic Program Partnership. The marine mammal data were collected and made freely available by the International MEOP Consortium and the national programs that contribute to it. (http://www.meop.net).

\section{References}

Amblas, D., \& Dowdeswell, J. A. (2018). Physiographic influences on dense shelf-water cascading down the Antarctic continental slope. Earth-Science Reviews, 185(August), 887-900. Retrieved from https://doi.org/10.1016/j.earscirev.2018.07.014 doi: 10.1016/j.earscirev.2018.07.014

Aoki, S., Ono, K., Hirano, D., \& Tamura, T. (2020). Continuous winter oceanic profiling in the Cape Darnley Polynya, East Antarctica. Journal of Oceanography, 76 (5), 365372. Retrieved from https://doi.org/10.1007/s10872-020-00550-w doi: 10.1007/ s10872-020-00550-w

Aoki, S., Yamazaki, K., Hirano, D., Katsumata, K., Shimada, K., Kitade, Y., ... Murase, H. (2020). Reversal of freshening trend of Antarctic Bottom Water in the AustralianAntarctic Basin during 2010s. Scientific Reports, 10(1), 1-8. Retrieved from https : // doi.org/10.1038/s41598-020-71290-6 doi: 10.1038/s41598-020-71290-6

Arrigo, K. R., \& van Dijken, G. L. (2003). Phytoplankton dynamics within 37 Antarctic coastal polynya systems. Journal of Geophysical Research: Oceans, 108(8). doi: 10.1029/2002jc001739

Baines, P. G., Condie, S., Jacobs, S., \& Weiss, R. (1998). Ocean, Ice and Atmosphere: Interactions at the Antarctic Continental Margins (Vol. 75).

Bindoff, N. L., Williams, G. D., \& Allison, I. (2001). Sea-ice growth and water-mass modification in the Mertz Glacier polynya, East Antarctica, during winter. Annals of Glaciology, 33, 399-406. doi: 10.3189/172756401781818185

Charrassin, J. B., Hindell, M., Rintoul, S. R., Roquet, F., Sokolov, S., Biuw, M., .. Guinet, C. (2008). Southern Ocean frontal structure and sea-ice formation rates revealed by elephant seals. Proceedings of the National Academy of Sciences of the United States of America, 105 (33), 11634-11639. doi: 10.1073/pnas.0800790105

Foster, T. D., \& Carmack, E. C. (1976). Frontal zone mixing and Antarctic Bottom water formation in the southern Weddell Sea. Deep-Sea Research and Oceanographic Abstracts, 23(4), 301-317. doi: 10.1016/0011-7471(76)90872-X

Fricker, H. A., Warner, R. C., \& Allison, I. (2000). Mass balance of the Lambert Glacier-Amery Ice Shelf system, East Antarctica: a comparison of computed balance fluxes and measured fluxes. Journal of Glaciology, 46(155), 561-570. doi: $10.3189 / 172756500781832765$

Galton-Fenzi, B. K., Hunter, J. R., Coleman, R., Marsland, S. J., \& Warner, R. C. (2012). Modeling the basal melting and marine ice accretion of the Amery Ice Shelf. Journal of Geophysical Research: Oceans, 117(9), 1-19. doi: 10.1029/2012JC008214

Gordon, A. L., \& Tchernia, P. L. (1972). Waters of the continental margin off Adélie Coast, Antarctica. Antarctic Research Series. Antarctica Oceanology II: The Australian-New Zealand Sector, 19, 59-69. doi: 10.1029/ar019p0059

Guo, G., Shi, J., Gao, L., Tamura, T., \& Williams, G. D. (2019). Reduced Sea Ice Production Due to Upwelled Oceanic Heat Flux in Prydz Bay, East Antarctica. Geophysical Research Letters, 46(9), 4782-4789. doi: 10.1029/2018GL081463

Gwyther, D. E., Spain, E. A., King, P., Guihen, D., Williams, G. D., Evans, E., .. Coleman, R. (2020). Cold Ocean Cavity and Weak Basal Melting of the Sørsdal Ice Shelf Revealed by Surveys Using Autonomous Platforms. Journal of Geophysical Research: Oceans, 125(6), 1-17. doi: 10.1029/2019JC015882

Haumann, F. A., Gruber, N., \& Münnich, M. (2020). Sea-Ice Induced Southern Ocean Subsurface Warming and Surface Cooling in a Warming Climate. AGU Advances, 1 (2). doi: 10.1029/2019av000132 
Hellmer, H. H. (2004). Impact of Antarctic ice shelf basal melting on sea ice and deep ocean properties. Geophysical Research Letters, 31(10), 1-4. doi: 10.1029/2004GL019506

Hemer, M. A., Hunter, J. R., \& Coleman, R. (2006). Barotropic tides beneath the Amery Ice Shelf. Journal of Geophysical Research: Oceans, 111(11), 1-2. doi: 10.1029/ 2006JC003622

Herraiz-Borreguero, L., Church, J. A., Allison, I., Peña-Molino, B., Coleman, R., Tomczak, M., \& Craven, M. (2016). Basal melt, seasonal water mass transformation, ocean current variability, and deep convection processes along the Amery Ice Shelf calving front, East Antarctica. Journal of Geophysical Research: Oceans, 121(7), 4946-4965. doi: $10.1002 / 2016 \mathrm{JC} 011858$

Herraiz-Borreguero, L., Coleman, R., Allison, I., Rintoul, S. R., Craven, M., \& Williams, G. D. (2015). Circulation of modified Circumpolar Deep Water and basal melt beneath the Amery Ice Shelf, East Antarctica. Journal of Geophysical Research: Oceans, 120 (4), 3098-3112. doi: 10.1002/2015JC010697

Labrousse, S., Williams, G., Tamura, T., Bestley, S., Sallée, J. B., Fraser, A. D., ... Charrassin, J. B. (2018). Coastal polynyas: Winter oases for subadult southern elephant seals in East Antarctica. Scientific Reports, 8(1), 1-15. doi: 10.1038/ s41598-018-21388-9

Liu, C., Wang, Z., Cheng, C., Wu, Y., Xia, R., Li, B., \& Li, X. (2018). On the Modified Circumpolar Deep Water Upwelling Over the Four Ladies Bank in Prydz Bay, East Antarctica. Journal of Geophysical Research: Oceans, 123(11), 7819-7838. doi: 10 $.1029 / 2018 \mathrm{JC} 014026$

Liu, C., Wang, Z., Cheng, C., Xia, R., Li, B., \& Xie, Z. (2017). Modeling modified Circumpolar Deep Water intrusions onto the Prydz Bay continental shelf, East Antarctica. Journal of Geophysical Research: Oceans, 122, 5189-5217. doi: 10.1038/175238c0

Liu, W., Lu, J., Xie, S. P., \& Fedorov, A. (2018). Southern Ocean Heat Uptake, redistribution, and storage in a warming climate: The role of meridional overturning circulation. Journal of Climate, 31 (12), 4727-4743. doi: 10.1175/JCLI-D-17-0761.1

Malpress, V., Bestley, S., Corney, S., Welsford, D., Labrousse, S., Sumner, M., \& Hindell, M. (2017). Bio-physical characterisation of polynyas as a key foraging habitat for juvenile male southern elephant seals (Mirounga leonina) in Prydz Bay, East Antarctica. PLoS ONE, 12(9), 1-24. doi: 10.1371/journal.pone.0184536

Massom, R. A., Harris, P. T., Michael, K. J., \& Potter, M. J. (1998). The distribution and formative processes of latent-heat polynyas in East Antarctica. Annals of Glaciology, 27, 420-426. doi: 10.3189/1998aog27-1-420-426

McMahon, C. R., Roquet, F., Baudel, S., Belbeoch, M., Bestley, S., Blight, C., ... Woodward, B. (2021). Animal Borne Ocean Sensors - AniBOS - An Essential Component of the Global Ocean Observing System. Frontiers in Marine Science, 8(November), 1-21. doi: $10.3389 /$ fmars.2021.751840

Mensah, V., Nakayama, Y., Fujii, M., Nogi, Y., \& Ohshima, K. I. (2021). Dense water downslope flow and AABW production in a numerical model: Sensitivity to horizontal and vertical resolution in the region off Cape Darnley polynya. Ocean Modelling, 165(June), 101843. Retrieved from https://doi.org/10.1016/j.ocemod .2021 .101843 doi: $10.1016 /$ j.ocemod.2021.101843

Mizuta, G., Fukamachi, Y., Simizu, D., Matsumura, Y., Kitade, Y., Hirano, D., ... Ohshima, K. I. (2021). Seasonal Evolution of Cape Darnley Bottom Water Revealed by Mooring Measurements. Frontiers in Marine Science, 8(August), 1-18. doi: $10.3389 /$ fmars.2021.657119

Morrison, A. K., McC. Hogg, A., England, M. H., \& Spence, P. (2020). Warm Circumpolar Deep Water transport toward Antarctica driven by local dense water export in canyons. Science Advances, 6(18), 1-10. doi: 10.1126/sciadv.aav2516

Nakata, K., Ohshima, K. I., \& Nihashi, S. (2021). Mapping of Active Frazil for Antarctic Coastal Polynyas, With an Estimation of Sea-Ice Production. Geophysical Research Letters, 48(6), 1-11. doi: 10.1029/2020GL091353

Narayanan, A., Gille, S. T., Mazloff, M. R., \& Murali, K. (2019). Water Mass Char- 
acteristics of the Antarctic Margins and the Production and Seasonality of Dense Shelf Water. Journal of Geophysical Research: Oceans, 124(12), 9277-9294. doi: 10.1029/2018JC014907

Nihashi, S., \& Ohshima, K. I. (2015). Circumpolar mapping of antarctic coastal polynyas and landfast sea ice: Relationship and variability. Journal of Climate, 28(9), 36503670. doi: 10.1175/JCLI-D-14-00369.1

Nunes Vaz, R. A., \& Lennon, G. W. (1996). Physical oceanography of the Prydz Bay region of Antarctic waters. Deep-Sea Research Part I: Oceanographic Research Papers, 43(5), 603-641. doi: 10.1016/0967-0637(96)00028-3

O'Brien, P. E., Cooper, A. K., Florindo, F., Handwerger, D. A., Lavelle, M., Passchier, S., ... Whitehead, J. M. (2004). Prydz channel fan and the history of extreme ice advances in Prydz Bay. In Proceedings of the ocean drilling program: Scientific results (Vol. 188, pp. 1-32). doi: 10.2973/odp.proc.sr.188.016.2004

Ohshima, K. I., Fukamachi, Y., Williams, G. D., Nihashi, S., Roquet, F., Kitade, Y., ... Wakatsuchi, M. (2013). Antarctic Bottom Water production by intense sea-ice formation in the Cape Darnley polynya. Nature Geoscience, 6(3), 235-240. Retrieved from http://dx.doi.org/10.1038/ngeo1738 doi: 10.1038/ngeo1738

Orsi, A. H., Smethie, W. M., \& Bullister, J. L. (2002). On the total input of Antarctic waters to the deep ocean: A preliminary estimate from chlorofluorocarbon measurements. Journal of Geophysical Research: Oceans, 107(8). doi: 10.1029/2001jc000976

Orsi, A. H., \& Wiederwohl, C. L. (2009). A recount of Ross Sea waters. Deep-Sea Research Part II: Topical Studies in Oceanography, 56 (13-14), 778-795. Retrieved from http: // dx.doi.org/10.1016/j.dsr2.2008.10.033 doi: 10.1016/j.dsr2.2008.10.033

Padman, L., Howard, S. L., Orsi, A. H., \& Muench, R. D. (2009). Tides of the northwestern Ross Sea and their impact on dense outflows of Antarctic Bottom Water. Deep-Sea Research Part II: Topical Studies in Oceanography, 56(13-14), 818-834. Retrieved from http://dx.doi.org/10.1016/j.dsr2.2008.10.026 doi: 10.1016/j.dsr2.2008 .10 .026

Rintoul, S. R. (1998). On the Origin and Influence of Adélie Land Bottom Water. ANTARCTIC RESEARCH SERIES. OCEAN, ICE, AND ATMOSPHERE: INTERACTIONS AT THE ANTARCTIC CONTINENTAL MARGIN, 75, 151-171. doi: $10.1029 / \operatorname{ar} 075 \mathrm{p} 0151$

Roquet, F., Williams, G., Hindell, M. A., Harcourt, R., McMahon, C., Guinet, C., .. Fedak, M. (2014). A Southern Indian Ocean database of hydrographic profiles obtained with instrumented elephant seals. Scientific Data, 1, 1-10. doi: 10.1038/sdata.2014.28

Sabu, P., Subeesh, M. P., Sivakrishnan, K. K., \& Anilkumar, N. (2021). Causes and impacts of anomalous warming in the Prydz Bay, East Antarctica during austral summer 201617. Polar Science(February), 100660. Retrieved from https://doi.org/10.1016/ j.polar.2021.100660 doi: 10.1016/j.polar.2021.100660

Schaffer, J., Timmermann, R., Arndt, J. E., Rosier, S. H. R., Anker, P. G. D., Callard, S. L., ... Roberts, D. H. (2019). An update to Greenland and Antarctic ice sheet topography, cavity geometry, and global bathymetry (RTopo-2.0.4) [data set]. PANGAEA. Retrieved from https://doi.org/10.1594/PANGAEA.905295 doi: 10.1594/PANGAEA.905295

Silvano, A., Rintoul, S. R., \& Herraiz-Borreguero, L. (2016). Ocean-ice shelf interaction in East Antarctica. Oceanography, 29(4), 130-143. doi: 10.5670/oceanog.2016.105

Silvano, A., Rintoul, S. R., Peña-Molino, B., Hobbs, W. R., Van Wijk, E., Aoki, S., ... Williams, G. D. (2018). Freshening by glacial meltwater enhances melting of ice shelves and reduces formation of Antarctic Bottom Water. Science Advances, 4(4), 1-12. doi: 10.1126/sciadv.aap9467

Smith, N. R., Zhaoqian, D., Kerry, K. R., \& Wright, S. (1984). Water masses and circulation in the region of Prydz Bay, Antarctica. Deep Sea Research Part A, Oceanographic Research Papers, 31 (9), 1121-1147. doi: 10.1016/0198-0149(84)90016-5

Tamura, T., Ohshima, K. I., Fraser, A. D., \& Williams, G. D. (2016). Sea ice production variability in Antarctic coastal polynyas. Journal of Geophysical Research: Oceans, 
1-14. doi: 10.1002/2015JC011537.Received

Tamura, T., Ohshima, K. I., \& Nihashi, S. (2008). Mapping of sea ice production for Antarctic coastal polynyas. Geophysical Research Letters, 35(7), 1-5. doi: 10.1029/ 2007GL032903

Wang, Q., Danilov, S., Hellmer, H. H., \& Schröter, J. (2010). Overflow dynamics and bottom water formation in the western Ross Sea: Influence of tides. Journal of Geophysical Research: Oceans, 115(10), 1-16. doi: 10.1029/2010JC006189

Wang, X., Zhang, Z., Wang, X., Vihma, T., Zhou, M., Yu, L., ... Sein, D. V. (2021). Impacts of strong wind events on sea ice and water mass properties in Antarctic coastal polynyas. Climate Dynamics. Retrieved from https://doi.org/10.1007/ s00382-021-05878-7 doi: 10.1007/s00382-021-05878-7

Whitworth, T., Orsi, A. H., Kim, S.-J., Nowlin, W. D., \& Locarnini, R. A. (1998). Water Masses and Mixing Near the Antarctic Slope Front. In Ocean, ice, and atmosphere: Interactions at the antarctic continental margin. antarctic research series (Vol. 75, pp. 1-27). doi: 10.1029/ar075p0001

Williams, G. D., Bindoff, N. L., Marsland, S. J., \& Rintoul, S. R. (2008). Formation and export of dense shelf water from the Adélie depression, East Antarctica. Journal of Geophysical Research: Oceans, 113(4), 1-12. doi: 10.1029/2007JC004346

Williams, G. D., Herraiz-Borreguero, L., Roquet, F., Tamura, T., Ohshima, K. I., Fukamachi, Y., ... Hindell, M. (2016). The suppression of Antarctic bottom water formation by melting ice shelves in Prydz Bay. Nature Communications, 7(6), 1-9. Retrieved from http://dx.doi.org/10.1038/ncomms12577 doi: 10.1038/ ncomms 12577

Williams, G. D., Hindell, M., Houssais, M. N., Tamura, T., \& Field, I. C. (2011). Upper ocean stratification and sea ice growth rates during the summer-fall transition, as revealed by Elephant seal foraging in the Adélie Depression, East Antarctica. Ocean Science, 7(2), 185-202. doi: 10.5194/os-7-185-2011

Wong, A. P., \& Riser, S. C. (2013). Modified shelf water on the continental slope north of Mac Robertson Land, East Antarctica. Geophysical Research Letters, 40(23), 61866190. doi: 10.1002/2013GL058125

Wong, A. P. S., Bindoff, N. L., \& Forbes, A. (1998). Ocean-Ice Shelf Interaction and Possible Bottom Water Formation in Prydz Bay, Antarctica. ANTARCTIC RESEARCH SERIES.OCEAN, ICE, AND ATMOSPHERE: INTERACTIONS AT THE ANTARCTIC CONTINENTAL MARGIN, 75, 173-187. doi: 10.1029/ar075p0173

Xu, Z., Gao, G., Xu, J., \& Shi, M. (2017). The evolution of water property in the Mackenzie Bay polynya during Antarctic winter. Journal of Ocean University of China, 16(5), 766-774. doi: 10.1007/s11802-017-3286-8 